\title{
Conditional Analysis of Turbulent Premixed and Stratified Flames on Local Equivalence Ratio and Progress of Reaction
}

\author{
* \\ M. Mustafa Kamal ${ }^{\mathrm{a}}$, Robert S. Barlow ${ }^{\mathrm{b}}$, Simone Hochgreb ${ }^{\mathrm{a}}$ \\ ${ }^{a}$ Department of Engineering, University of Cambridge, CB2 1PZ, Cambridge, United Kingdom \\ ${ }^{\mathrm{b}}$ Sandia National Laboratories, California, United States of America
}

\begin{abstract}
Previous studies on the Cambridge/Sandia stratified burner have produced a comprehensive database of line Rayleigh/Raman/CO LIF measurements of scalars, as well as LDA and PIV measurements of velocity, for flames under non-uniform mixture fraction, under moderate turbulent conditions where the ratio of the turbulent velocity fluctuations to the laminar flame speed is of order 10. In prior work, we applied multiple conditioning methods to demonstrate how local stratification increases the levels of CO and $\mathrm{H}_{2}$, relative to the corresponding turbulent premixed flame, and enhances surface density function (SDF) and scalar dissipation rate of progress of reaction (SDR), based on extent of temperature rise, at a particular location in the flame where the mixing layer and flame brush cross. In the present study, we examine the global features of selected flames at all locations, by obtaining probability density functions (PDFs) for species concentrations, SDRs, and SDFs, conditioned on local equivalence ratio and location in the flame brush throughout the domain.

We find that for most cases, species profiles as a function of temperature are well represented by laminar flame relationships at the local equivalence ratio, with some deviations attributable to either differential diffusion near the flame base and local stratification effects further downstream where the flame brush crosses the mixing layer. In particular, $\mathrm{CO}_{2}$ is significantly affected by differential diffusion, and $\mathrm{CO}$ and $\mathrm{H}_{2}$ by stratification. However, the stratification effects on the species are relatively minor when conditioned on local equivalence ratio, a simplifying result in the context of modelling.

Measurements of the gradient of progress of reaction and scalar dissipation rates, conditioned on local equivalence ratio, show that the thermal zone of the flame is thickened by turbulence: the mean SDF and SDR values are in general lower than those of unstrained laminar flames. The effect is greater under rich conditions, with conditional mean SDR decreasing to less than half of the corresponding laminar value. The extent of flame thickening is the same in the premixed as the stratified case, once the stratified measurements are conditioned on the same equivalence ratio.
\end{abstract}

\footnotetext{
* Corresponding author

Email address:mmk44@cam.ac.uk
} 
Keywords: Turbulent combustion, Lean stratified combustion, Laser diagnostics, Co-annular jet burner, Bluff-body stabilized flame, Surface density function, Scalar dissipation rate 


\section{Introduction}

In many practical devices, combustion takes place under turbulent stratified conditions, where fuel and oxidiser are not homogeneously mixed. Such a mixing strategy is often implemented intentionally, in order to extend the lean flammability limits and to achieve flame stability over a wider range of global stoichiometry. A consequence of the strategy is the presence of significant variations in reactant concentrations, which affects the rate of flame propagation and local pollutant formation.

Many experimental and numerical investigations have been undertaken to study turbulent flame propagation through spatially non-inhomogeneous mixture conditions in order to understand the effects of stratification on flame behaviour [1-10] [11-15]. The observed stratification effects depend strongly on the particular operating conditions (laminar or turbulent) and burner geometry (e.g. V-flame, bluff-body stabilized, piloted, combustion bomb). Under laminar and low turbulence conditions, heat and radicals from burnt richer regions feed the leaner regions, thus increasing the flame resistance to extinction, as demonstrated in laminar experiments and simulations [11] [12] [16]. A number of low Reynolds number DNS simulations have also demonstrated the effects of stratification on the global heat release rate. The sensitivity to stratification was found to depend on the extent of stratification, turbulence intensity and length scale [17] [18] [19] [20]. In general, higher turbulence levels increase strain and lower the relative importance of the equivalence ratio gradients.

A number of test burners with controlled boundary conditions and practically relevant turbulence levels [1] [2] [3] [4] [5] have been tailored to study the effect of stratification on flammability limits [6], flame thickness [7] [8] [9], flame surface density and scalar dissipation rate [7] [8], flame propagation speed [6] [10], as well as its macro- and microstructure [21] [22]. The studies have shown that stratification widens the lean flammability limits relatively to premixed cases [23], and that the mass fractions of $\mathrm{CO}$ and $\mathrm{H}_{2}$ species can be affected [21] [22]. Mean effects of stratification on flame surface density [7] [8], curvature [8, 24], and flame thickness [7] [8] [9] [10], are relatively less pronounced. However, a few studies have identified a memory effect, and a corresponding increase in flame propagation rate relatively to premixed conditions [10, 11] [12] [13] [24].

Recent studies on the structure of stabilized stratified flames provide a suitable database for testing model assumptions. The Darmstadt group produced a turbulent stratified flame series with high levels of turbulence and stabilized by an inner stoichiometric pilot flame. These flames have been studied by Böhm et al. [3], Kuenne et al. [25], and Seffrin et al. [2] using Rayleigh and Raman scattering for scalars, and LDA measurements for velocity. Examining instantaneous temperature profiles and corresponding $\mathrm{OH}$ PLIF images, Böhm et al. [3] concluded that the effect of stratification on temperature profiles is secondary to that of the heat transport effect due to the three-dimensional flame geometry. A number of LES simulations continue to be used for comparison to the Darmstadt experimental database to understand the relative effects of stratification, turbulence, and heat transfer [26] [27] [28].

The Cambridge/Sandia stratified swirl burner was designed with two purposes in mind: (a) in complement to the Darmstadt burner, to produce a database of scalars and velocities for turbulent 
numerical model validation, now with a recirculation zone and (in some cases) swirl, and (b) to produce simultaneous scalar gradient information that can reveal the microstructure of scalars in premixed and stratified flames. The detailed database of scalars, velocity, and surface temperatures has been extensively discussed in a number of publications [21] [22] [29] [30] [31] [32] [33] [34]. Regarding point (a), the database produced has been recently used for comparison with LES numerical simulations [35] [36] [37] [38], providing insight into the potential successes and shortcomings of the various modelling approaches for premixed and stratified flames [39] [40]. Mean and rms measurements are available in [41]. In particular, the detailed database led to the discovery that molecular transport has a strong effect on the transport of $\mathrm{H}_{2} \mathrm{O}$ and $\mathrm{CO}_{2}$ near the base of the flame, leading to an accumulation of the latter relatively to the former in recirculation zones [30], a phenomenon subsequently confirmed by simulations [42].

The experimental studies also provided a rich database of the probability distribution functions (PDFs) of scalars and their gradients, which has not been sufficiently explored or compared to models, particularly after conditioning on the local equivalence ratio. In many modelling approaches for stratified flames, the two key variables involved are the progress of reaction, $c$, (defined in more detailed further on, but here taken as linearly related to temperature) and the local mixture fraction. In particular, the mean gradient of the progress of reaction, $\nabla c$, denoted the surface density function (SDF), and the corresponding scalar dissipation rate (SDR), $\chi_{c}=D \nabla c \cdot \nabla c$, are directly related to the mixing rate and thus to the reaction rate. Sweeney et al. [21] [22] [29] demonstrated how local stratification affects the SDF and SDR at a particular location in the flame, where the mixing layer and flame brush cross [29]. That study showed that for the same local equivalence ratio, an increase in the local gradient of mixture fraction leads to increased scalar dissipation.

In the present study, rather than considering the very narrow question of the effect of the local gradient of mixture fraction, as was done in [29], we examine the global features of the stratified flame, by analysing the statistics of species mass fractions, SDR, and SDF, conditioned on local equivalence ratio and location in the flame brush throughout the flame, using the same original dataset. The present paper therefore has the following objectives: (a) to compare the PDFs of state space of the scalars (species and temperature) to that of unstrained laminar flames, conditioned on the local equivalence ratio; (b) similarly, to compare the PDFs of gradients of progress of reaction and scalar dissipation values, conditioned on equivalence ratio, and (c) to compare the resulting PDFs of equivalence ratio and progress of reaction with numerical simulations of Proch and Kempf [37].

\section{Experimental details}

\subsection{Cambridge/Sandia stratified swirl burner}

The burner has been described in previous publications, but the outlet geometry is reproduced in Fig. 1, from [21]. The burner was designed to generate reacting flow conditions representative of turbulent flows in practical systems, including sufficiently high turbulence levels, swirl, and operation under premixed and 
stratified conditions. The inlets consisted of co-annular tubes with a development length exceeding 25 hydraulic diameters to ensure well-developed turbulent flow. A ceramic central bluff body was used to stabilize the flame with minimal heat loss - measured surface temperatures are available in [34]. Mass flow controllers were used to control the equivalence ratio of the inner annulus $\left(\phi_{i}\right)$ and the outer annulus $\left(\phi_{o}\right)$ independently, allowing the stratification ratio $\left(S R=\phi_{i} / \phi_{o}\right)$ to be varied for a fixed global equivalence ratio $\left(\phi_{g}\right)$.

\subsection{Operating conditions}

The operating conditions analysed in the present study are shown in Table 1, spanning premixed and stratified cases without swirl. The fixed bulk velocities were chosen to maximize the Reynolds numbers in the flows given the physical constraints imposed by the mass flow controllers available and the maximum throughput of the laboratory air supply. The bulk velocity in the outer annulus, $U_{o}=18.7 \mathrm{~m} / \mathrm{s}$, was set at more than twice the value of the velocity in the inner annulus, $U_{i}=8.3 \mathrm{~m} / \mathrm{s}$, in order to generate substantial levels of shear and thus turbulence between the two flows. Co-flow air was supplied around the outer annulus with a bulk velocity $U_{c o}=0.4 \mathrm{~m} / \mathrm{s}$ to prevent the entrainment of ambient air and to provide well-characterized boundary conditions. The Reynolds numbers $(R e=\rho U L / \mu)$ are $R e_{i}=5960$ for the inner flow and $R e_{o}=11500$ for the outer flow, based on bulk velocities at the exit, the hydraulic diameter of each annulus, and gas properties evaluated at $294 \mathrm{~K}$. The total power varies from $25.8 \mathrm{~kW}$ in the premixed cases to $21.5 \mathrm{~kW}$ in the moderately stratified case and $19.3 \mathrm{~kW}$ for the highly stratified cases. The stratification ratio, SR, defined as the ratio of the nominal equivalence ratio in the inner annulus to that in the outer, was varied from 1 for premixed cases to 3 for the most stratified cases. The flames burn in the thin flame zone of the Borghi diagram, where we expect that the reaction zone is not disrupted by turbulence, but the thermal zone is.

\subsection{Multi-scalar diagnostics}

Raman-Rayleigh line measurements were obtained from experiments at the Turbulent Combustion Laboratory (Sandia National Laboratories). The setup allows for the line measurement of temperature (Rayleigh scattering) and major species: $\mathrm{CH}_{4}, \mathrm{CO}_{2}, \mathrm{CO}, \mathrm{H}_{2}, \mathrm{H}_{2} \mathrm{O}$ and $\mathrm{O}_{2}$ (via Raman scattering and COLIF), with simultaneous cross-planar OH-PLIF to define the flame orientation relative to the measurement line. Beams from four frequency doubled Nd:YAG lasers were used for Raman and Rayleigh line imaging, with a total energy of $1.8 \mathrm{~J} /$ pulse in the probe volume. The species and temperature profiles were obtained by translating the $6.18 \mathrm{~mm}$ probe volume through each flame in slightly overlapping steps, with 500 shots acquired at each step. The focus had a diameter of approximately $0.22 \mathrm{~mm}\left(1 / \mathrm{e}^{2}\right)$. The projected binnedpixel spacing for the combined Raman/Rayleigh/CO-LIF data was $103 \mu \mathrm{m}$, which is larger than the $\sim 60 \mu \mathrm{m}$ optical resolution of the system. The resolution must be compared to a thermal thickness of the laminar unstrained flame around $500 \mu \mathrm{m}$. Turbulent velocity measurements by Zhou et al. [31] place the 
Kolmogorov length scale around $30 \mu \mathrm{m}$ in the middle of the shear layer between inner and outer annular flows (non-reacting) at a downstream distance of $\mathrm{z}=30 \mathrm{~mm}$. The experimental setup and the uncertainties introduced in the evaluation of the derived quantities are discussed in detail in [21], but are under 5\% for most species mass fractions, except $\mathrm{CO}$ and $\mathrm{H}_{2}(10 \%)$, and around $2 \%$ for temperature.

\section{Data analysis}

A brief synopsis of the data analysis methodologies employed to calculate derived quantities from the experimental measurements is provided for reference.

\subsection{Progress variable, $c$}

A progress variable ideally represents the extent to which the energy in the fuel has been released by reaction, such as enthalpy. In computational work, the fuel, oxygen or the sum of carbon monoxide and dioxide are often chosen as markers of reaction progress in a flame, normalized by the difference between their initial and equilibrium values. In experimental work, we seek quantities that are both easily and accurately measurable. The differences between selected markers for an unstrained premixed flame are shown in Fig. 2, as calculated using Chemkin [43] for an unstrained flame using GRI Mech 3.0 and multicomponent transport [44]. The choice of marker does affect the measure, and clearly oxygen consumption and the sum of carbon monoxide and dioxide agree more closely with temperature than the fuel. All of the markers are affected by their own molecular diffusion relative to the bulk mixture, and are inherently biased $^{1}$. However, so long as any comparisons to predictions are made on a consistent basis, almost any marker can be used.

The present work makes use of a two distinct reaction progress variables. In the case of the measurement of gradients of progress of reaction, covering most of the paper, the sensible progress variable is temperature, owing to the high relative accuracy, but particularly the higher resolution of the measurement relatively to the species. For specific comparisons with the studies of Proch and Kempf, a different progress of reaction based on $\mathrm{CO}+\mathrm{CO}_{2}+\mathrm{H}_{2}$ is used to calculate a flame sensor, as outlined further on, so that a consistent formulation is adopted.

In a purely premixed flame the progress of reaction based on temperature is based on the normalization of the local flame temperature rise relative to the unburned reactants by the maximum temperature rise achievable at the local equivalence ratio:

$$
c=\frac{T-T_{u}}{T_{e}(\phi)-T_{u}}
$$

\footnotetext{
${ }^{1}$ In principle, a conversion of temperature to enthalpy would offer an almost ideal marker of progress of reaction, were it not for the possibility of super-adiabatic rich flames under high Lewis number conditions. However, uncertainties in the estimation of the relative specific heats of the mixtures as a function of temperature would quickly overwhelm any perceived improvement.
} 
where $T$ is the local temperature, $T_{u}$ is the temperature in the unburned reactants, and $T_{e}$ is the equilibrium temperature in the burned products. Since the equivalence ratio varies in a stratified flame, the equilibrium temperature $T_{e}$ must be calculated at the locally measured equivalence ratio $\phi$, as discussed in Section 3.2.

\subsection{Equivalence ratio, $\phi$}

A reconstructed equivalence ratio, representing the demand for oxygen based on the local mass fractions of hydrogen and carbon to the locally available oxygen, can be obtained from the major species measured, such that it remains constant in the reactants and products. Using the atomic balance of the measured species molar fractions, $X_{\mathrm{i}}$, we have:

$$
\phi=\frac{X_{\mathrm{CO}_{2}}+2 X_{\mathrm{CH}_{4}}+X_{\mathrm{CO}}+0.5\left(X_{\mathrm{H}_{2} \mathrm{O}}+X_{\mathrm{H}_{2}}\right)}{X_{\mathrm{CO}_{2}}+X_{\mathrm{O}_{2}}+0.5\left(X_{C O}+X_{\mathrm{H}_{2} \mathrm{O}}\right)}
$$

This definition of equivalence ratio from Eq. (2) yields values that are close to those calculated using the scaled Bilger mixture fraction $Z$ [45]:

$$
\phi_{\mathrm{B}}=\frac{Z}{1-Z} \frac{1-Z_{s}}{Z_{s}} \approx \phi
$$

where the subscripts $B$ and $s$ refer to the Bilger definition and the stoichiometric value respectively. Carbonand hydrogen-containing species in general have different molecular weights and diffuse at different rates. Hydrogen $\left(\mathrm{H}_{2}\right)$ and water $\left(\mathrm{H}_{2} \mathrm{O}\right)$ are lighter molecules than carbon monoxide $(\mathrm{CO})$ and carbon dioxide $\left(\mathrm{CO}_{2}\right)$, with the result that they diffuse faster through the preheat zone, ahead of $\mathrm{CO}_{2}$ and $\mathrm{CO}$. Therefore, whereas the total flux $\mathrm{C}$ or $\mathrm{H}$ atoms is conserved across the ends of a one-dimensional flame, the local weighted mass or molar fractions may vary. This phenomenon is illustrated in Fig. 3, where the simulated reconstructed equivalence ratio is plotted as a function of temperature for premixed flames, as calculated using Chemkin [43] and GRI Mech 3.0 [44] with multi-component transport and the Soret effect included, for strains of zero and $1000 \mathrm{~s}^{-1}$. The effect differential diffusion on local equivalence ratio is particularly pronounced for richer flames, as there is a larger concentration of species with diffusion different than the bulk nitrogen.

The effects of differential molecular diffusion have been found to be particularly important in bluff-body stabilized flames [30], where the flame brush is located in the high shear region adjacent to the recirculation zone. As explained in [30] and confirmed by calculations of a laminar bluff-body flame [42], lighter, hydrogen containing products $\left(\mathrm{H}_{2} \mathrm{O}\right.$ and $\left.\mathrm{H}_{2}\right)$ diffuse more quickly than $\mathrm{CO}$ and $\mathrm{CO}_{2}$ toward the reactants. The $\mathrm{CO}_{2}$-deficient gases within the preheat zone are then transported downstream, leaving higher $\mathrm{CO}_{2}$ levels, lower $\mathrm{O}_{2}$ levels, and higher equivalence ratio in the recirculating products, relative to those expected in a one-dimensional flame. This effect becomes apparent in the turbulent measurements, and is further discussed in the Results section. 


\subsection{Flame sensor indicator, $\Omega$}

Many numerical computations use an indicator to identify the region of the flame brush. In order to compare the PDFs obtained in the experiments to the numerical calculations of Proch and Kempf [37], we use the same definition of the flame sensor in the measurements as in the numerical computations. The progress variable used in [37] is calculated from the sum of the mass fractions of major species $\left(Y_{C}=Y_{C_{2}}+\right.$ $Y_{C O}+Y_{\mathrm{H}_{2}}$ ). The flame sensor in the numerical calculations is defined as the normalized gradient of the progress variable relative to the maximum value based on one-dimensional Cantera flame computations. The flame sensor takes a value of zero in the fully burnt or unburnt regions, increasing up to unity at the point of maximum gradient of the progress of reaction defined by $Y_{C}$, then decreasing towards the products.

$$
\Omega=\left[\left(\frac{\frac{d Y_{C}(x)}{d x}}{\max \left(\frac{d Y_{C}(x)}{d x}\right)}\right)\right]
$$

The experimental values of the flame sensor variable are obtained from the measured mass fraction using central differencing, for comparison with numerical simulations.

\subsection{Surface density function, $|\nabla c|$}

The surface density function (SDF) or gradient of progress variable, $|\nabla c|$, is calculated using a second order central-differencing scheme, with forward- and back-scattering schemes applied at the edges of the line measurement data as described in [21]. The three-dimensional gradients of progress variable are obtained from the one-dimensional value along the line measurement axis by dividing these gradients by the cosine of the solid angle, $\theta$ between the local 3D flame normal:

$$
|\nabla c|=\left|\frac{d c}{d n}\right|=\left|\frac{(d c / d x)}{\cos \theta}\right|
$$

The angle $\theta$ is obtained from two cross planar OH PLIF images separated by 64 degrees, symmetrically about the direction of flow, as described in [46]. This correction assumes that near the flame front defined by the peak $\mathrm{OH}$ gradient, temperature gradients are locally parallel to those of $\mathrm{OH}$. This direction is assumed to be the same throughout the local flame.

\subsection{Scalar dissipation rate, $\chi_{c}$}

The scalar dissipation rate for the progress variable, $\chi_{c}$, is calculated as:

$$
\chi_{c}=\alpha|\nabla c|^{2}
$$

The thermal diffusivity, $\alpha$, is obtained by interpolating a lookup table of calculated values in temperature and equivalence ratio $\alpha(\phi, T)$ from premixed unstrained flames at a given $\phi$. Simulations estimate the maximum error to the thermal diffusivity to be within $10 \%$ [47]. 


\section{Flow and Flame Patterns}

Flame and flow patterns for this burner have been presented in previous investigations, but a summary of the key features are reproduced here for guidance. Natural luminosity photographs of the three cases listed in Table 1 are shown in the top row of Fig. 4. In all three cases the flames are attached and stabilize on the perimeter of the central bluff body. The flame luminosity increases as the inner region becomes richer from SwB1 to SwB9, and the high luminosity region is closer to the flame stabilization point.

The mean flow patterns including maps of 2D mean velocity, $\bar{U}=\sqrt{\bar{u}^{2}+\bar{v}^{2}}$, and fluctuating velocity, $U^{\prime}=\sqrt{u^{\prime 2}+v^{\prime 2}}$, derived from PIV [31] are shown in the middle row in Fig. 4. The two-dimensional flow fields demonstrate features typical of co-annular jet flow over a central bluff body: a recirculation zone is formed on the bluff body, with a zero velocity contour separating the surrounding shear flow. A second high velocity shear flow forms surrounding the inner region. The peak turbulent fluctuations appear in the shear zones separating the two annuli. The size of the recirculation zone decreases as the inner mixture becomes richer, and the flow accelerates beyond the region due to thermal expansion

An illustration of the distribution of equivalence ratio is provided by instantaneous and mean contours plots of equivalence ratio generated using artificially thickened flame LES simulations by Proch et al. [37], on the bottom row of Fig. 4. The simulations illustrate the mixing between streams and between the outer stream and the surrounding co-flow. The isolines of the flame sensor variable (Eq. 4), which determine the reacting region, are shown in white.

\section{Results}

The presentation and discussion of results are structured as follows. First we consider the correlations between equivalence ratio distribution and progress of reaction throughout the flame to understand the equivalence ratio distribution for premixed (SwB1), moderately stratified (SwB5), and highly stratified flames (SwB9) as a function of the downstream locations along the flame. Next, the thermal and compositional evolution of the flames is analysed, by plotting the joint PDFs of mass concentration of species and temperature conditioned on equivalence ratio. Finally, we examine conditioned surface density function and scalar dissipation rates, also as a function of location and equivalence ratio.

\subsection{Equivalence ratio distribution}

One measure of success of a reacting flow model is the ability to make predictions of the evolution of equivalence ratio (or mixture fraction) and progress of reaction. On the other hand, many models make $a$ priori assumptions about the PDFs of $\phi$ or $c$ and their relationship to the variance and mean via the relevant joint PDF [48] [49]. In this section we compare the measured and computed joint PDFs of $\phi$ and $c$ as a function of axial location. 
Figure 5 shows the evolution of the joint PDFs of $c$ and $\phi$, for the range of mean (Favre-averaged) progress of reaction $\tilde{c}$, between 0.01 to 0.99 , as a function of axial distance and position in the flame brush for the three flames listed in Table 1 . Near the base $(z=10$ and $20 \mathrm{~mm})$ each flame behaves as a premixed flame burning at the nominal equivalence ratio of the inner annular flow; the flame has yet to reach the mixing layer in the stratified cases. At these locations, we observe an increase in equivalence ratio towards the product side, even under premixed conditions. As documented in [31] and outlined in Section 3.2, this has been shown to result from differential molecular diffusion between carbon vs. hydrogen containing species, combined with the fact that the flame is stabilized in a high shear region between the bluff-body recirculation zone and the high-velocity reactant flow from the inner annulus. This preferential transport effect has also been explored in the laminar calculations by Katta et al. [42] and incorporated into a model in the LES work of Nambully et al. [35] [36]. At these near-field locations we also observe that the distribution along $c$ is bimodal, with peaks in cold reactants and burnt products, as expected for the regime of thin turbulent flames ${ }^{2}$. However, the product peak appears around $0.8<c<0.9$ rather than unity. Here the burnout zone that would exist in a planar turbulent flame without shear is merged and coupled with the recirculation zone. Thus, the apparent incomplete extent of reaction may result from the effect of heat loss from the recirculation zone to the bluff body surface [34], the limited reaction time due to high shear and turbulence [48], and possibly effects of differential diffusion, which alters the transport of enthalpy across the flame [30]. Further downstream we find a more normal structure that allows $c$ to approach unity in both premixed and stratified cases.

At $\mathrm{z}=30 \mathrm{~mm}$ in the two stratified cases (SwB5 and SwB9) the flame begins to burn into the mixing layer. Radial profiles of Favre average $\mathrm{T}$ and $\phi[21]$ show that the mixing layer is wider than the flame brush at all locations where they interact $(\mathrm{z} \geq 30 \mathrm{~mm})$, so the joint PDF's show broad distributions in $\phi$ at each value of $c$. As the flames become more stratified, a strong correlation appears between higher values of $T$ and $c$, in other words, complete reaction takes place preferably under conditions closer to stoichiometric.

With increasing streamwise distance, as the two mixing layers between inner reactant flow, outer reactant flow, and air co-flow merge, the PDFs start to show evidence of dilution of the reactants by air. This happens later in the premixed case because the flame speed across the inner annular flow is lower ( $\phi$ of 0.75 versus 1.0 and 1.125$)$.

Figure 6 shows a quantitative comparison between measured equivalence ratio distributions and LES simulation results from Proch et al. [37]. The range of equivalence ratios between 0.45-1.2 is divided into 100 bins to construct the PDFs, $p(\phi)$ for points inside the reacting zone, as defined the flame sensor over the range $0.01<\Omega<0.99$. The model assumes a reaction cut-off at the expected flammability limit of $\phi=0.45$ [38]. Accordingly, for consistency of comparisons, the experimental distribution is also clipped at a value of 0.45 .

\footnotetext{
${ }^{2}$ The reader is reminded that the Favre-averaged variable is limited to the range between 0.01 and 0.99 while the local progress variable is allowed to vary between 0 and 1 .
} 
Near the base of the flame $(\mathrm{z}=10 \mathrm{~mm})$, where the flame brush is still burning across the homogeneous mixture from the inner annular flow, the prediction shows a delta function for $\phi$, while the experimental data show a narrow Gaussian distribution with width corresponding to the rms measurement uncertainty of roughly 2 percent.

Further along the streamwise direction, the prediction shows a more rapid spreading of the conditional equivalence ratio distribution toward leaner mixtures than is observed in the experiments. This is particularly apparent in the two stratified cases (SwB5 and SwB9). The experimental PDFs for these stratified flames display the behaviour described in Figure 5, with narrow distributions near the base at $\mathrm{z}=10$ and $20 \mathrm{~mm}$, followed by a gradual spreading of the distribution toward leaner mixtures. This reflects the progress of the flame across the turbulent mixing layer, which further downstream includes entrained air from the coflow. The predicted distributions in the stratified cases extend toward leaner mixtures already at $\mathrm{z}=20 \mathrm{~mm}$. This trend continues to the last measurement station at $\mathrm{z}=70 \mathrm{~mm}$ suggesting that the predicted conditional PDFs are always leaner than measured values, and predicted mixing rates are too high.

Details of turbulent mixing models under high shear and high temperature gradients are not well tested, so perhaps the imperfect agreement is to be expected. On the other hand, the predicted mean radial profiles of mean temperature and equivalence ratio are not far from the measurements [37], which suggests that it is possible to make good mean predictions even when the details of the distributions are not perfectly captured.

\subsection{Conditioned species state space maps}

One limit for the turbulent flame behaviour is the structure of a laminar flame (unstrained or strained) at the local equivalence ratio considered. If the flame microstructure is not sufficiently disrupted, the relationship between progress of reaction and species concentration should remain intact. Direct measurements of strain in the present system are not available from the velocity measurements [31] due to spatial resolution limitations. However, measured mean velocity gradients indicate maximum strain rates of the order of $1000 \mathrm{~s}^{-1}$. The relationship between temperature and species concentration is shown in Fig. 7, for both unstrained and strained flames at a strain rate of $1000 \mathrm{~s}^{-1}$, as calculated using Chemkin [43] and GRI Mech 3.0 [44] with multicomponent transport and the Soret effect. The mass fractions of $\mathrm{O}_{2}$ and $\mathrm{H}_{2} \mathrm{O}$ are hardly sensitive to stoichiometry, lining up nearly on the same curve, up to the point where all methane disappears. $\mathrm{CH}_{4}, \mathrm{CO}$ and $\mathrm{H}_{2}$ are strong functions of the local stoichiometry, and $\mathrm{CO}_{2}$ shows some sensitivity to stoichiometry over most of the reaction zone. Only $\mathrm{CO}_{2}$ and $\mathrm{CO}$ (at low equivalence ratio) are sensitive to strain, with $\mathrm{CO}_{2}$ increasing and $\mathrm{CO}$ decreasing with strain.

Figure 8 shows scatter plots of measured species mass fraction versus temperature at an axial distance 50 $\mathrm{mm}$ downstream of the inlet, including all local equivalence ratios and locations, similar to those reported in $[8,21]$. This axial location corresponds approximately to the point where the flame brush crosses the center of the mixing layer between inner and outer annular flows. The proportion of measurements is represented by color coding of the PDF. Calculated curves for free laminar flames at equivalence ratios 0.60, 0.75 and 1.10 are also shown. For $\mathrm{O}_{2}, \mathrm{H}_{2} \mathrm{O}$ and $\mathrm{CO}_{2}$, the mean curves at this location agree 
reasonably well with the laminar calculations at an equivalence ratio of 0.75 . This is not surprising, since Fig. 5 shows that at this location, the mean equivalence ratio is about 0.75 for all flames, while these species are not very sensitive to equivalence ratio (Fig. 7). However, the concentrations for $\mathrm{H}_{2}, \mathrm{CO}$ and $\mathrm{CH}_{4}$ are scattered over a wide region, delimited by the concentrations obtained at the highest and leanest equivalence ratios.

Figure 9 shows mass fractions of the measured species within the flame brush, as a function of temperature, but now colored by equivalence ratio. Mean values and standard deviations are generated by binning in temperature space in steps of $20 \mathrm{~K}$. Unstrained laminar flame calculations are shown for reactant equivalence ratios $0.60,0.75$ and 1.10 . Close to the burner inlet, the local equivalence ratio is richer for the stratified mixtures (see Fig. 5), as the incoming flows have not yet mixed, so that the profiles follow those of the corresponding mixtures. Further downstream, the equivalence ratio is lowered by mixing between streams, and eventually with the surrounding co-flow air. As expected from the laminar calculations, the mass fractions of $\mathrm{O}_{2}, \mathrm{CO}_{2}$, and $\mathrm{H}_{2} \mathrm{O}$ are not strongly affected by the wide range of stoichiometry, compared to the wide variations for $\mathrm{CH}_{4}, \mathrm{CO}$, and $\mathrm{H}_{2}$. These variations are largely bracketed by the range of laminar flame curves at different equivalence ratios, and suggest the next logical step of conditioning results on the local equivalence ratio.

The mass fractions of $\mathrm{CH}_{4}, \mathrm{H}_{2} \mathrm{O}, \mathrm{CO}_{2}, \mathrm{CO}$, and $\mathrm{H}_{2}$, conditioned on the local equivalence ratio are plotted in Figs. 10-14, respectively, as functions of temperature, for the premixed ( $\mathrm{SwB} 1)$ and highly stratified (SwB9) cases, colored by the respective PDFs. Mean fits and standard deviations are generated by binning the species data in temperature space in steps of $20 \mathrm{~K}$. In each figure, both unstrained and strained calculations at the mean equivalence ratio for each bin are included.

For $\mathrm{CH}_{4}, \mathrm{H}_{2} \mathrm{O}$, and $\mathrm{O}_{2}$ (not shown) there is very good agreement between measured conditional means and the corresponding laminar flame calculations, either strained or unstrained (which are very similar), except for measured results at $\phi=0.40$, which is below the flammability limit and has no corresponding laminar calculation. Measured samples below the flammability limit can be accounted for by the fact that, far from the base, partially burned gases have mixed with surrounding air.

With the exception of results at $\mathrm{z}=10 \mathrm{~mm}$, the measured mean $\mathrm{CO}_{2}$ mass fractions conditioned on local equivalence ratio (Fig. 12) agree well with the strained laminar calculation at the corresponding equivalence ratio. The strain value of $1000 \mathrm{~s}^{-1}$ is estimated from the PIV velocity measurements near the base, but it is not necessarily representative further downstream. Nevertheless, a significant result from Fig. 12 is the fact that at $\mathrm{z}=50 \mathrm{~mm}$, where the flame crosses the center of the mixing layer in the stratified case (SwB9), agreement between the conditional mean measurements of $\mathrm{CO}_{2}$ and the corresponding strained laminar curve is comparable in both stratified and premixed flames, indicating that stratification by itself has little influence on $\mathrm{CO}_{2}$. The conditional mean $\mathrm{CO}_{2}$ mass fraction results at $\mathrm{z}=10 \mathrm{~mm}$ align significantly above the strained laminar curves in both flames, due to preferential transport effects near the base of these bluff-body stabilized flames [30, 50]. As explained in Section 3.2, $\mathrm{CO}_{2}$ diffuses more slowly than the hydrogen-carrying species, so that under conditions of very high shear 
at the base of the flame, the lighter species within the preheat zone are swept downstream, while the recirculation zone and the entire flame profile become enriched in $\mathrm{CO}_{2}$. Further downstream, the effect is not so pronounced because the flame becomes decoupled from the recirculation zone. This has also been demonstrated experimentally by Magnotti and Barlow [51] for rich premixed flames stabilized on a bluff body, and numerically by Katta and Roquemore [42].

In previous work [29] the effects of stratification on flame structure were isolated by using the location of peak CO mass fraction in each instantaneous line measurement as a surrogate for the location of peak heat release and analysing only those instantaneous realizations from the stratified flames that had the same local equivalence ratio as the premixed flame at the $\mathrm{CO}$ peak location. These multiply-conditioned comparisons, which retained only a small fraction of samples, showed that $\mathrm{CO}$ and $\mathrm{H}_{2}$ levels were increased by stratification, a result that is qualitatively consistent with calculations of lean, backsupported, stratified flames [19]. Here we consider how $\mathrm{CO}$ and $\mathrm{H}_{2}$ are affected by stratification in the region of high variance of equivalence ratio, where the flame brush interacts with the mixing layer $(\mathrm{z} \geq 30 \mathrm{~mm})$.

In the case of $\mathrm{CO}$ (Fig. 13), the peaks in the conditional mean values are consistent with the corresponding unstrained laminar calculations for both premixed and stratified flames. In contrast with $\mathrm{CO}_{2}$, the strained calculations lower the peak $\mathrm{CO}$, leading to worse agreement with the measurements. At temperatures below the point of peak $\mathrm{CO}$, the measured mean values are somewhat higher than the laminar calculations, with differences slightly greater in the stratified flame than in the premixed flame. This can be seen by comparing the SwB9 mean results conditioned on $\phi=0.75$ at $z=50$ and $70 \mathrm{~mm}$ with the SwB1 results at those locations. This difference may well be an effect of stratification, with elevated CO levels from the richer product zones diffusing toward the leaner preheat region of the flame. However, the effect is relatively small when all of the data at the given local equivalence ratio are included. Note also that the rms fluctuations for $\mathrm{CO}$ conditioned on $\phi=0.75$ are similar in the stratified and premixed flames.

Considering the same comparisons for $\mathrm{H}_{2}$ (Fig. 14) we find that the effects of stratification appear somewhat greater than for CO. Specifically, the conditional mean mass fraction curves for $\mathrm{H}_{2}$ at $\mathrm{z}=50 \mathrm{~mm}$ in the stratified flame (SwB9), where the flame is roughly centered on the mixing layer, are higher than the laminar curves by more than is seen in the premixed flame (SwB1) or further downstream in the stratified flame. Conditional rms fluctuations are also higher in the stratified flame than in the premixed flame. The higher mean values may result from the high diffusivity of $\mathrm{H}_{2}$, which can promote the transport of $\mathrm{H}_{2}$ from richer portions of the flame. This is further emphasized by the fact that the difference between the mean mass fractions in the premixed and stratified flames at $\mathrm{z}=50 \mathrm{~mm}$ for the common equivalence ratio of 0.75 is smaller than the differences among the conditional mean curves at different different equivalence ratios. Note that these $\mathrm{H}_{2}$ mass fractions correspond to very low mole fractions, making $\mathrm{H}_{2}$ the most difficult of the present species to measure with good precision.

A key point in the present observations is that species mass fractions are primarily a function of the local equivalence ratio, and secondarily affected by stratification. This had been suggested by studies by Kuenne 
et al. [25] on the Darmstadt flames, as well as in the preliminary assessments of the effect of stratification by Sweeney et al. [21]. Here it becomes clear that the statistical significance of the instantaneous effects of stratification identified in [29] is relatively small.

\subsection{Surface density function (SDF) and thermal scalar dissipation rate (SDR)}

The mean gradients of temperature, in the form of the surface density function (SDF, Eq. 6), $|\nabla c|$, and the thermal scalar dissipation rate (SDR, Eq. 5), $\chi_{c}$, are connected to the flame surface density and the rate of reaction [52] [53] [54] [55] [56]. For example, the local flame surface density (FSD) at a particular location in the flame brush defined by the density averaged progress of reaction $\tilde{c}$, and an instantaneous local extent of reaction, $c$, is the product of the local SDF to the probability of finding the particular value of $c$ at that location $p(c ; \tilde{c})$ :

$$
\Sigma(c ; \tilde{c})=\langle p(c ; \tilde{c})|\nabla c|\rangle_{c \tilde{c}}
$$

The quantity can be related to the overall rate of reaction once integrated over all locations and progress of reaction [57] [58]. In all cases, the SDR is proportional to the rate of mixing, and thus at the limit of high reaction rates, to the rate of heat release. In a previous paper, Sweeney et al. [4] showed that the FSD of the present flames did not change with stratification, even though the local SDF changed with operating condition. This was explained by the fact that changes in SDF with operating conditions are compensated by inverse changes in the corresponding PDF-the higher the gradient, the lower the probability of finding a particular value of $c$. Thus, the overall unconditioned FSD over the flame brush remains unchanged by stratification.

Here we consider the values of the SDF and SDR conditioned on the local equivalence ratio, compared to the corresponding values for calculated laminar flames. Figure 15 shows the local surface density function and scalar dissipation rate as a function of progress of reaction, for the range of mean (Favreaveraged) progress of reaction, $\tilde{c}$ between 0.01 and 0.99 , for different axial locations along the flame. The data is colored by local equivalence ratio to highlight any composition dependent effects. Points below the lean flammability limit $(\phi=0.47)$ are plotted in black to illustrate any extension of the lean limit and/or entrainment from coflow. The scatter plots for both SDF and SDR exhibit a broad distribution of data within each bin especially at downstream locations beyond $\mathrm{z}=20 \mathrm{~mm}$, regardless of the degree of stratification. For the premixed flame, we note that the values of SDF and SDR are lower than the unstrained laminar limit, particularly further downstream. For the stratified flames, the behaviour is approximately bracketed by the behaviour at the extremes in equivalence ratio, with exceptions in the richer flames discussed further on. Overall the mean profiles of SDF and SDR are significantly lower than laminar unstrained values at the corresponding nominal mean stoichiometries. The comparison is worse for the stratified case SwB9 at the base of the flame, where the measured temperature gradients are significantly lower than the laminar values, particularly around the peak. This may be related to the heat loss near the stabilization point. The mean values of SDF and SDR become relatively independent of the 
stratification further downstream, with approximately the same values from $\mathrm{z}=50 \mathrm{~mm}$ onwards. The large scatter about the mean value arises from the significant variation in the instantaneous temperature profiles, which arises from the small eddies penetrating the thermal zone, as evidenced by the individual shots shown by Sweeney et al. [21]. Instantaneous temperature profiles show small but regular local peaks and troughs in the temperature (and by extension, progress variable) profiles across the thermal ramp, which indicates significant stirring by turbulent eddies. The discrepancies become larger towards the richer, higher gradient regions, which might suggest experimental error. However, the resolution of the measured profiles is 100 microns, which should be sufficient to resolve the thermal zone of a free flame with 5-10 points, as demonstrated in [51]. The differences indeed become larger for the richer cases — this may be a result of higher differential diffusion or the very fact that higher gradients are destroyed by the presence of turbulence, which tends to lower the mean gradients by convective motion. The SDR profiles in Fig. 15b closely follow the SDF profiles in Fig. 15a, but with the peak skewed towards the products, as the thermal diffusivity is higher towards that end.

The present results of a thickening of flames with turbulence are in good agreement with those reported in [59] [60] [61] [62, 63] for turbulent premixed flames. In those studies, thicker instantaneous flames have been measured relative to laminar values, with a peak skewed towards the reactants relative to laminar calculations. Similar results have also been obtained in high turbulence DNS simulations [63].

The measurements also indicate that the use of ensembles of unstrained laminar flame calculations do not capture the mean behaviour of the mean surface density function. Instead, the results suggest that the main effect of turbulence is to thicken the thermal flame zone via eddies of length comparable or smaller than the flame thickness penetrating the flame zone, rather than to thin them by strain.

The discussion related to the effects of stratification on SDF and SDR becomes clearer once the measurements are conditioned by the local equivalence ratio. Joint PDFs of the normalized SDF and SDR as a function of progress variable, conditioned on the equivalence ratio across the flame brush, are plotted in Figs. 16 and 17, respectively, for cases SwB1 (premixed) and SwB9 (most stratified). In each case, comparisons are made with the values for the corresponding unstrained and strained $\left(1000 \mathrm{~s}^{-1}\right)$ laminar flame values at the respective equivalence ratio. The calculated unstrained values are lower than the strained values under lean conditions, whereas the reverse is true for the rich case $(\phi=1.1)$. In the premixed case, we observe that at the base of the flame, measurements are not far from the unstrained laminar limit case. At this location the flame stabilizes in the relatively low turbulence, yet high strain region that exists between the inner annulus flow and the recirculation zone as reported in [31]. Further downstream, there is significant variance, with lower mean values, as the turbulence caused by the shear-generated vortices disrupts the thermal layer. Under lean conditions, strain thins a laminar flame, so that strained flame profiles lie further away from the experimentally measured results. The behaviour of the SDF and SDR in the lean range is similar for both stratified and premixed flames, with the conditioned values slightly below the laminar values. A useful observation for both SDF and SDR, as with the conditional mean species mass fractions, is that mean and rms results are very similar in the premixed case (SwB1) and the stratified case (SwB9), when conditioned 
on equivalence ratio 0.75 , at $\mathrm{z}=50 \mathrm{~mm}$, where the flame brush crosses the center of the mixing layer in the stratified flame. For the richer conditions $(\phi=1.12)$, however, the measured values are significantly lower than the laminar counterpart, particularly at the base. This behaviour has been observed in rich flames near the base of a bluff-body stabilized flame [51], and has been attributed to differential transport and Lewis number effects as explained in the previous discussion. At rich equivalence ratios, strain thickens the flame slightly, leading to lower gradients, so that the comparison with strained values is favourable, yet a factor of two higher than the measurements indicates.

The thickening of the pre-flame zone under lean conditions has been previously reported for lean flames $[59,60,62,63]$. Here we demonstrate the effect prevails for premixed and stratified flames, and highlight the differences in behaviour between lean and rich ranges. Whereas the effect is clear, further work is still necessary, either via DNS or experiments, to clearly demonstrate the interaction between turbulence length scales relatively to the diffusive thickness, and the role of strain and turbulence in not only in thermal zone, but also in the reaction region. 


\section{Conclusions}

This work has analysed the behaviour of stable species $\left(\mathrm{H}_{2} \mathrm{O}, \mathrm{H}_{2}, \mathrm{CO}_{2}, \mathrm{CO}, \mathrm{O}_{2}, \mathrm{CH}_{4}\right)$, measured by line Raman scattering and CO LIF, and temperature gradients, measured by line Rayleigh scattering, in three non-swirling, bluff-body stabilized, premixed and stratified turbulent methane flames, as measured in the work of Sweeney et al. [21] [29]. The species mass fractions were conditioned on the local equivalence ratio, for comparisons of the state space as a function of the local temperature, for locations across the whole flame domain. These profiles were then compared to the calculated laminar strained and unstrained profiles at the corresponding equivalence ratio.

The premixed flame state space profiles agree well with the laminar profiles, with the exception of deviations near the base of the flame, which can be attributed to the previously documented effect of differential transport in bluff-body stabilized flames. A central result of the present study is that the species profiles as a function of temperature for the stratified cases largely agree with premixed laminar flame calculations once the experimental data are conditioned on the local equivalence ratio. Deviations were observed near the flame base, again due to differential transport effects. Further downstream, where the flame brush burns across the stratified mixing layer, the mass fractions of $\mathrm{CH}_{4}, \mathrm{O}_{2}, \mathrm{CO}_{2}$, and $\mathrm{H}_{2} \mathrm{O}$, conditioned on local equivalence ratio as a function of temperature agree well with laminar calculations at the corresponding equivalence ratio, both for premixed and stratified cases. The conditioned mass fractions of $\mathrm{CO}$ and $\mathrm{H}_{2}$ appear somewhat higher than in the corresponding laminar calculations for temperatures below those at the peak $\mathrm{CO}$ and $\mathrm{H}_{2}$ mass fractions. This higher level elevation of $\mathrm{CO}$ and $\mathrm{H}_{2}$ is consistent with qualitative expectations, based upon previous experimental and computational studies of lean, back-supported, stratified flame. However, the observed effect is relatively minor, suggesting that the flame microstructure is largely controlled by the local stoichiometry, with only minor effects of strain and stratification.

The measurements of the mean gradient of progress of reaction and scalar dissipation rates (corrected for the 3D direction of the flame normal), are in all cases lower than the strained $\left(1000 \mathrm{~s}^{-1}\right)$ and unstrained laminar flame values, indicating a thickening of the thermal flame zone.

The flame thickening is results from disruption of the preheat zone by turbulent eddies at spatial scales smaller than the thermal laminar flame thickness. At lean conditions, the SDF values are about $60-90 \%$ of the laminar unstrained value, whereas at rich conditions they reduce to about $50 \%$ of that value. Lean flames under strain are thinner than their unstrained counterparts, so the addition of strain makes the comparisons between turbulent measurements and laminar calculations worse. On the other hand, rich laminar flames under strain become somewhat thicker, so addition of strain can account for part of the difference.

We conclude based on the measurements of the microstructure of premixed and stratified flames that the effect of turbulence is to generally thicken the flame relatively to strained or unstrained calculations at all 
equivalence ratios. This general sub thermal scale effect promotes the additional diffusion of species and heat in relatively equal manner, so that the overall relationship between temperature and species is not significantly disrupted, and the species-temperature relationships remain similar to those from laminar flame calculations.

\section{Acknowledgements}

M. Mustafa Kamal acknowledges funding from University of Engineering and Technology Peshawar (Pakistan). The measurements at Sandia National Labs were sponsored by the United States Department of Energy, Office of Basic Energy Sciences, Division of Chemical Sciences, Geosciences and Biosciences. Sandia National Laboratories is a multiprogram laboratory operated by Sandia Corporation, a Lockheed Martin Company, for the United States Department of Energy under contract DE-AC04-94-AL85000. The authors also thank Dr. Akihiro Hayakawa for his contributions to the laminar flame calculations and Dr. Saravanan Balusamy for his valuable suggestions about the data processing. 


\section{References}

[1] P. C. Vena, B. Deschamps, G. J. Smallwood, and M. R. Johnson, Proc. Combust. Inst. (2011) 15511558.

[2] F. Seffrin, F. Fuest, D. Geyer, and A. Dreizler, Combust. Flame, 157 (2010) 384-396.

[3] B. Böhm, J. H. Frank, and A. Dreizler, Proc. Combust. Inst. 33 (2011) 1583-1590.

[4] M. S. Sweeney, S. Hochgreb, M. J. Dunn, and R. S. Barlow, Proc. Combust. Inst. 33 (2011) 14191427.

[5] C. Galizzi and D. Escudié, Combust. Flame, 157 (2010) 2277-2285.

[6] T. Kang and D. C. Kyritsis, Proc. Combust. Inst. 31 (2007) 1075-1083.

[7] P. Anselmo-Filho, S. Hochgreb, R. S. Barlow, and R. S. Cant, Proc. Combust. Inst. 32 (2009) 17631770.

[8] M. S. Sweeney, S. Hochgreb, and R. S. Barlow, Combust. Flame, 158 (2011) 935-948.

[9] V. Robin, A. Mura, M. Champion, O. Degardin, B. Renou, and M. Boukhalfa, Combust. Flame, 153 (2008) 288-315.

[10] N. Pasquier, B. Lecordier, M. Trinité, and A. Cessou, Proc. Combust. Inst. 31 (2007) 1567-1574.

[11] T. Kang and D. C. Kyritsis, Comb. Sci. Tech. 177 (2005) 2191-2210.

[12] A. P. Da Cruz, A. M. Dean, and J. M. Grenda, Proc. Combust. Inst. 28 (2000) 1925-1932.

[13] C. Galizzi and D. Escudié, Combust. Flame, 145 (2006) 621-634.

[14] M. S. Mansour, R. W. Bilger, and R. W. Dibble, Combust. Flame, 85 (1991) 215-231.

[15] A. Bonaldo and J. B. Kelman, Combust. Flame, 156 (2009) 750-762.

[16] R. Zhou and S. Hochgreb, Combust. Flame, 160 (2013) 1070-1082.

[17] D. C. Haworth, R. J. Blint, B. Cuenot, and T. J. Poinsot, Combust. Flame, 121 (2000) 395-417.

[18] C. Jiménez, B. Cuenot, T. J. Poinsot, and D. C. Haworth, Combust. Flame, 128 (2002) 1-21.

[19] E. S. Richardson, V. E. Granet, A. Eyssartier, and J. H. Chen, Combust. Theor. Model. 14 (2010) 775792.

[20] J. Hélie and A. Trouvé, Proc. Combust. Inst. 27 (1998) 891-898.

[21] M. S. Sweeney, S. Hochgreb, M. J. Dunn, and R. S. Barlow, Combust. Flame, 159 (2012) 2896-2911.

[22] M. S. Sweeney, S. Hochgreb, M. J. Dunn, and R. S. Barlow, Combust. Flame, 159 (2012) 2912-2929.

[23] R. K. Green and C. C. Zavier, P. I. Mech. Eng. A - J. Pow. (1992) 59-64.

[24] B. Renou, E. Samson, and A. Boukhalfa, Comb. Sci. Tech. 176 (2004) 1867-1890.

[25] G. Kuenne, F. Seffrin, F. Fuest, T. Stahler, A. Ketelheun, D. Geyer, et al., Combust. Flame, 159 (2012) 2669-2689.

[26] F. Cavallo Marincola, T. Ma, and A. M. Kempf, Proc. Combust. Inst. 34 (2013) 1307-1315.

[27] R. Mercier, P. Auzillon, V. Moureau, N. Darabiha, O. Gicquel, D. Veynante, et al., Flow Turbul. Combust., 93 (2014) 349-381.

[28] P. Trisjono, K. Kleinheinz, H. Pitsch, and S. Kang, Flow Turbul. Combust., 92 (2014) 201-235. 
[29] M. S. Sweeney, S. Hochgreb, M. J. Dunn, and R. S. Barlow, Combust. Flame, 160 (2013) 322-334.

[30] R. S. Barlow, M. J. Dunn, M. S. Sweeney, and S. Hochgreb, Combust. and Flame, 159 (2012) 25632575.

[31] R. Zhou, S. Balusamy, M. S. Sweeney, R. S. Barlow, and S. Hochgreb, Combust. Flame, 160 (2013) 2017-2028.

[32] M. M. Kamal, C. Duwig, S. Balusamy, R. Zhou, and S. Hocgreb, ASME Turbo Expo 2014: Gas Turbine Technical Conference and Exposition, Dusseldorf, Germany, 2014.

[33] M. M. Kamal, R. Zhou, S. Balusamy, and S. Hochgreb, Proc. Combust. Inst. 35 (2015) 3803-3811.

[34] M. Euler, R. Zhou, S. Hochgreb, and A. Dreizler, Combust. Flame, 161 (2014) 2842-2848.

[35] S. Nambully, P. Domingo, V. Moureau, and L. Vervisch, Combust. Flame, 161 (2014) 1756-1774.

[36] S. Nambully, P. Domingo, V. Moureau, and L. Vervisch, Combust. Flame, 161 (2014) 1775-1791.

[37] F. Proch and A. M. Kempf, Combust. Flame, 161 (2014) 2627-2646.

[38] R. Mercier, T. Schmitt, D. Veynante, and B. Fiorina, Proc. Combust. Inst. 35 (2015) 1259-1267.

[39] S. H. Kim, J. Comput. Phys. 285 (2015) 193-207.

[40] R. Mokhtarpoor, H. Turkeri, and M. Muradoglu, Comput. Fluids, 105 (2014) 39-57.

[41] M. S. Sweeney, R. Zhou, M. J. Dunn, R. S. Barlow, and S. Hochgreb. Cambridge-Sandia Swirl Burner Database, 2015. < http://www-g.eng.cam.ac.uk/reactingflows/databases/SwB/database.html>.

[42] V. Katta and W. M. Roquemore, Proc. Combust. Inst. 34 (2013) 1101-1108.

[43] CHEMKIN, 2011. <http://www.reactiondesign.com/products/chemkin/chemkin-2/>.

[44] B. Gardiner, B. Yan, Z. Qin, G. Smith, D. Crosley, M. Golden, et al. GRI 3.0. <http://www.me.berkeley.edu/gri_mech/>.

[45] R. W. Bilger, S. H. Starner, and R. J. Kee, Combust. Flame, 80 (1990) 135-149.

[46] A. N. Karpetis, T. B. Settersten, R. W. Schefer, and R. S. Barlow, Opt. Lett., 29 (2004) 355-357.

[47] M. S. Sweeney, PhD Thesis, Department of Engineering, University of Cambridge, Cambridge, 2011.

[48] M. M. Salehi, W. K. Bushe, N. Shahbazian, and C. P. T. Groth, Proc. Combust. Inst. 34 (2013) 12031211.

[49] O. R. Darbyshire, N. Swaminathan, and S. Hochgreb, Comb. Sci. Tech. 182 (2010) 1141-1170.

[50] R. S. Barlow, M. J. Dunn, and G. Magnotti, Combust. Flame, 162 (2015) 727-735.

[51] G. Magnotti and R. S. Barlow, Combust. Flame, 162 (2015) 100-114.

[52] D. Veynante and L. Vervisch, Prog. Energy Combust. Sci., 285 (2002) 193-266.

[53] K. Bray, P. Domingo, and L. Vervisch, Combust. Flame, 141 (2005) 431-437.

[54] N. Peters, J. Fluid Mech, 384 (1999) 107-132.

[55] S. M. Martin, J. C. Kramlich, G. Kosály, and J. J. Riley, J. Eng. Gas Turb. Power, 125 (2003) 895 900.

[56] A. Y. Klimenko and R. W. Bilger, Prog. Energy Combust. Sci., 25 (1999) 595-687.

[57] N. Peters, Proc. Combust. Inst. 21 (1986) 1231-1250.

[58] F. A. Williams, Combustion Theory, 2nd ed. Menlo Park, California, 1988. 
[59] F. O'Young and R. W. Bilger, Combust. Flame, 109 (1997) 682-700.

[60] Y. C. Chen and R. W. Bilger, Combust. Flame, 131 (2002) 400-435.

[61] R. Sankaran, E. R. Hawkes, J. H. Chen, T. Lu, and C. H. Law, Proc. Combust. Inst., 31 (2007) 12911298.

[62] A. Soika, F. Dinkelacker, and A. Leipertz, Proc. Combust. Inst., 27 (1998) 785-792.

[63] A. Y. Poludnenko and E. S. Oran, Combust. Flame, 157 (2010) 995-1011. 


\section{Figure Captions}

Figure 1. Top and side view of the burner geometry exit. The arrows indicate the direction of flow and swirl [21].

Figure 2. Comparison of different progress variables using temperature, $c_{T}$ (solid blue), oxygen, $c_{\mathrm{O} 2}$ (dotted line) and $\mathrm{CO}+\mathrm{CO}_{2}+\mathrm{H}_{2}, c_{C}$ (dotted line) as obtained from unstrained laminar premixed flame calculations at $\phi=0.75$.

Figure 3. Calculated reconstructed equivalence ratios (Eq. 2) obtained from the species mole fractions in unstrained (thick lines) and strained (thin lines) laminar flames at a strain of $1000 \mathrm{~s}^{-1}$.

Figure 4. Top row: Photographs of the flames studied in the present work [22]. Middle row: Mean $(\mathrm{r}<0)$ and fluctuating $(\mathrm{r}>0)$ velocity maps. Streamlines are shown in black for $\mathrm{r}<0 \mathrm{~mm}$ [31]; Bottom row: Calculated instantaneous $(r<0)$ and mean $(r>0)$ contour plots of equivalence ratio, $\phi$, with the lean flammability limit marked by a black isoline. The flame sensor variable $\Omega$, which marks the combustion region, is denoted by white isolines [37].

Figure 5. Joint PDFs of equivalence ratio, $\phi$, as a function of progress variable, $c$, (left) and as a function of temperature, $T$, (right) within the flame brush $(0.01<\tilde{c}<0.99)$ at various axial locations (in $\mathrm{mm}$ ). Conditional means are plotted in blue, while vertical blue bars denote one standard deviation.

Figure 6. PDFs of equivalence ratio $\phi$, within the reacting zone, conditioned on flame sensor value, $0.01<\Omega<0.99$, at different axial locations, $z$ (in $\mathrm{mm}$ ) for cases SwB1, SwB5, and SwB9. The dotted blue lines represent the experimental data and the solid red lines the LES simulations.

Figure 7. Species mass fractions and temperature for unstrained (solid lines) and strained (1000 s' 1) (dotted lines) mass fractions from laminar premixed calculation, for a range of values of equivalence ratio.

Figure 8. Joint PDFs of temperature $T$ and species mass fraction $Y_{i}$, colored by the corresponding joint probability, within the flame brush $(0.01<\tilde{c}<0.99)$ for premixed (SwB1), moderately stratified (SwB5), and highly stratified (SwB9) cases at axial location $z=50 \mathrm{~mm}$. Mean values, binned in $20 \mathrm{~K}$ steps, are plotted in blue, while vertical blue bars denote one standard deviation. The black solid line represents unstrained laminar flame calculations at the nominal mean equivalence ratio $\left(\phi_{n}=0.75\right)$ while $\phi=0.60$ and $\phi=1.10$ are represented by dashed line and small circles respectively. 
Figure 9. Scatter plots of temperature $T$ and species mass concentration $Y_{i}$, coloured by the equivalence ratio, within the flame brush $(0.01<\tilde{c}<0.99)$, for SwB1, SwB5, and SwB9 datasets, at different axial locations, $z$. Mean values are plotted in pink, while vertical pink bars denote one standard deviation. The black lines represents unstrained laminar flame calculations at equivalence ratios of 0.6 (dashed line), 0.75 (solid line) and 1.10 (circles).

Figure 10. Mass fraction of $\mathrm{CH}_{4}$ plotted as a function of temperature, conditioned on equivalence ratio and colored by the number of points, represented by the PDF, for cases SwB1 and SwB9 at various axial locations. Mean values are plotted in blue, while vertical blue bars denote one standard deviation. Black solid lines represent the unstrained laminar calculations and dotted lines represent the strained $\left(1000 \mathrm{~s}^{-1}\right)$ laminar flame calculations, at the midpoint of the equivalence ratio bin.

Figure 11. Mass fraction of $\mathrm{H}_{2} \mathrm{O}$ plotted as a function of temperature, conditioned on equivalence ratio and colored by the number of points, represented by the PDF (in logarithmic scale), for cases SwB1 and SwB9 for various axial locations. Mean values are plotted in blue, while vertical blue bars denote one standard deviation. Black solid lines represent the unstrained laminar calculations and dotted lines represent the strained $\left(1000 \mathrm{~s}^{-1}\right)$ laminar flame calculations, at the midpoint of the equivalence ratio bin.

Figure 12. Mass fraction of $\mathrm{CO}_{2}$ plotted as a function of temperature, conditioned on equivalence ratio and colored by the number of points, represented by the PDF, for cases SwB1 and SwB9 at various axial locations. Mean values are plotted in blue, while vertical blue bars denote one standard deviation. Black solid lines represent the unstrained laminar calculations and dotted lines represent the strained $\left(1000 \mathrm{~s}^{-1}\right)$ laminar flame calculations, at the midpoint of the equivalence ratio bin.

Figure 13. Mass fraction of $\mathrm{CO}$ plotted as a function of temperature, conditioned on equivalence ratio and colored by the number of points, represented by the PDF (in logarithmic scale), for cases SwB1 and SwB9, for various axial locations. Mean values are plotted in blue, while vertical blue bars denote one standard deviation. Black solid lines represent the unstrained laminar calculations and dotted lines represent the strained $\left(1000 \mathrm{~s}^{-1}\right)$ laminar flame calculations, at the midpoint of the equivalence ratio bin.

Figure 14. Mass fraction of $\mathrm{H}_{2}$ plotted as a function of temperature, conditioned on equivalence ratio and colored by the number of points, represented by the PDF (in logarithmic scale), for cases SwB1 and SwB9 for various axial locations. Mean values are plotted in blue, while vertical blue 
bars denote one standard deviation. Black solid lines represent the unstrained laminar calculations and dotted lines represent the strained $\left(1000 \mathrm{~s}^{-1}\right)$ laminar flame calculations, at the midpoint of the equivalence ratio bin.

Figure 15. Scatter plots of surface density function (a) and scalar dissipation rate (b) in progress variable space for the SwB1, SwB5, and SwB9 datasets. Points for which $\phi<0.47$ (flammability limit) are plotted in black. Mean values are plotted in pink, while vertical bars denote one standard deviation. Laminar flame calculations at the global equivalence ratio $\left(\phi_{g}=0.75\right)$ are plotted in black; unstrained laminar flame calculations for $\phi=0.60$ and $\phi=1.10$, are plotted as dashed line and circles, respectively. The SDF is normalized by the value of laminar flame thickness $\left(\delta_{L}=0.588\right.$ $\mathrm{mm}$ ) derived from laminar flame calculations at an equivalence ratio of $\phi=0.75$. The SDR is normalized by the term $\left(\delta_{L} / S_{L}\right)$; where $S_{L}$ is the laminar flame speed of the methane/air flame $\left(S_{L}=0.214 \mathrm{~m} / \mathrm{s}\right)$.

Figure 16. SDF as a function of progress of reaction, colored by the corresponding joint probability, conditioned on the local equivalence ratio, within the flame brush $(0.01<\tilde{c}<0.99)$. Mean values are plotted in blue, while vertical bars denote one standard deviation. Black solid lines represent the unstrained laminar calculations and dotted lines represent the strained $\left(1000 \mathrm{~s}^{-1}\right)$ laminar flame calculations, at the midpoint of the equivalence ratio bin. See Fig. 15 for normalization factors.

Figure 17. SDR as a function of progress of reaction, colored by the PDF, and conditioned on the local equivalence ratio, for all positions across the flame. Mean fits are plotted as solid lines, along with variances as error bars. Black solid lines represent the unstrained laminar calculations and dotted lines represent the strained $\left(1000 \mathrm{~s}^{-1}\right)$ laminar flame calculations, at the midpoint of the equivalence ratio bin. See Fig. 11 for normalization factors. 


\section{Table Captions}

Table 1. Operating conditions for Cambridge/Sandia Stratified Swirl Burner considered in this study, including the inner $\phi_{i}$, outer $\phi_{o}$ and global equivalence ratio, $\phi_{g}$, and the ratio of the total turbulent velocity $U^{\prime}$ to laminar flame speed at the global equivalence ratio, $S_{\mathrm{L}}$, determined as the maximum value in the radial direction for a for a given axial location, $z$. In all cases $U_{i}=8.3 \mathrm{~m} / \mathrm{s}$ and $U_{o}=18.7 \mathrm{~m} / \mathrm{s}$, and $U_{c o}=0.4 \mathrm{~m} / \mathrm{s}$. 


\begin{tabular}{|c|c|c|c|c|c|c|c|c|}
\hline \multirow[b]{2}{*}{ Case } & \multirow[b]{2}{*}{ SR } & \multirow[b]{2}{*}{$\phi_{i}$} & \multirow[b]{2}{*}{$\phi_{o}$} & \multirow[b]{2}{*}{$\phi_{g}$} & \multicolumn{4}{|c|}{$U^{\prime} / S_{L}$} \\
\hline & & & & & $\begin{array}{c}\mathrm{z}=10 \\
\mathrm{~mm}\end{array}$ & $\begin{array}{c}\mathrm{z}=\mathbf{3 0} \\
\mathrm{mm}\end{array}$ & $\begin{array}{c}\mathrm{z}=50 \\
\mathrm{~mm}\end{array}$ & $\begin{array}{c}\mathrm{z}=70 \\
\mathbf{m m}\end{array}$ \\
\hline$S w B 1$ & 1 & 0.75 & 0.75 & 0.75 & 9.72 & 10.05 & 9.82 & 9.82 \\
\hline SwB5 & 2 & 1.00 & 0.50 & 0.75 & 9.30 & 10.06 & 10.16 & 9.55 \\
\hline$S w B 9$ & 3 & 1.13 & 0.375 & 0.75 & 9.95 & 10.13 & 10.01 & 9.61 \\
\hline
\end{tabular}

Table 1. Operating conditions for Cambridge/Sandia Stratified Swirl Burner considered in this study, including the inner $\phi_{i}$, outer $\phi_{o}$ and global equivalence ratio, $\phi_{g}$, and the ratio of the total turbulent velocity $U^{\prime}$ to laminar flame speed at the global equivalence ratio, $S_{\mathrm{L}}$, determined as the maximum value in the radial direction for a for a given axial location, $z$. In all cases $U_{i}=8.3 \mathrm{~m} / \mathrm{s}$ and $U_{o}=18.7 \mathrm{~m} / \mathrm{s}$, and $U_{c o}=0.4 \mathrm{~m} / \mathrm{s}$. 
Figure-1
Click here to download high resolution image

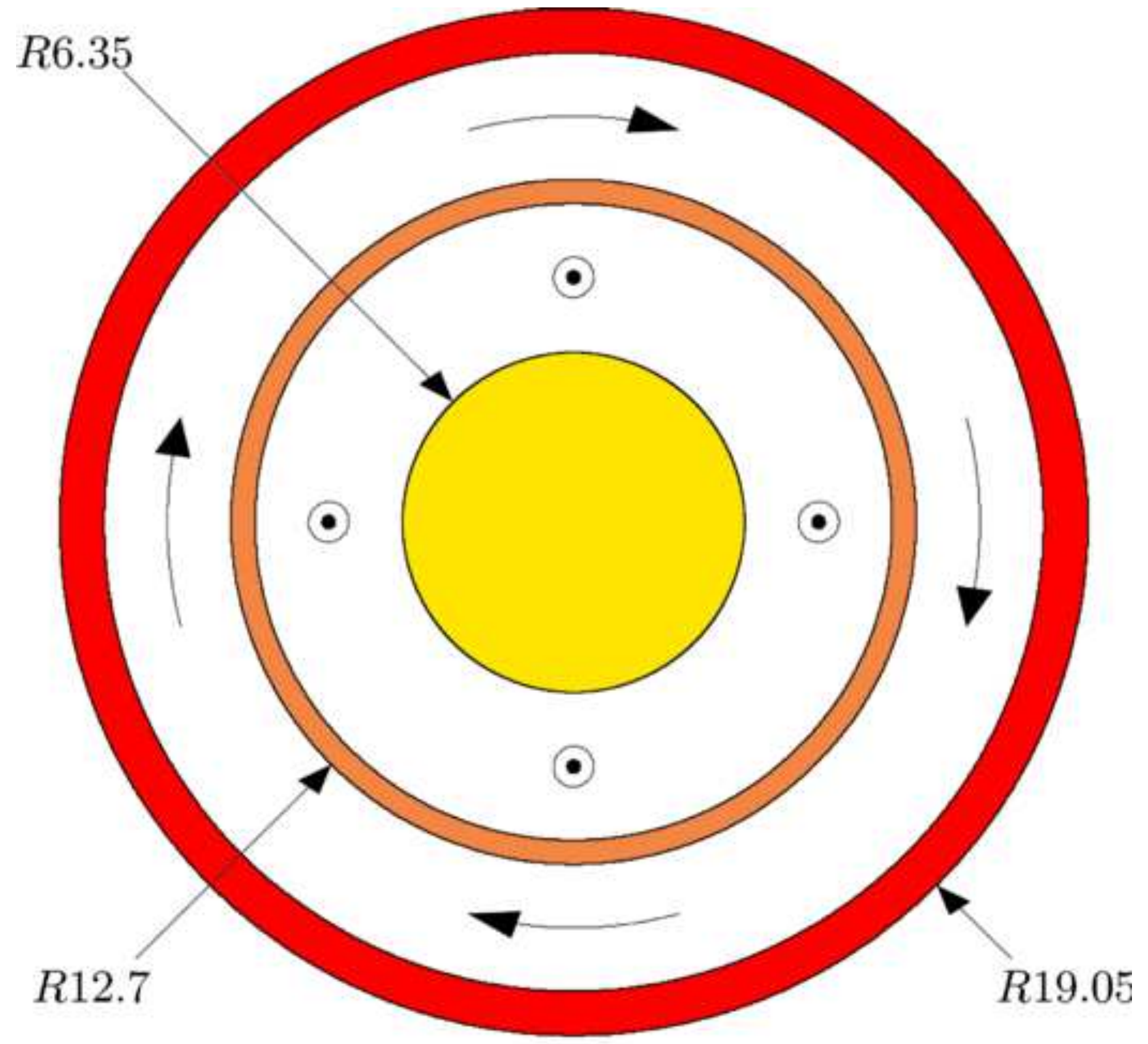

0.9

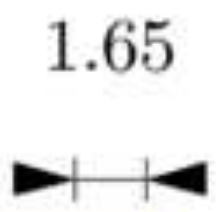

1.65
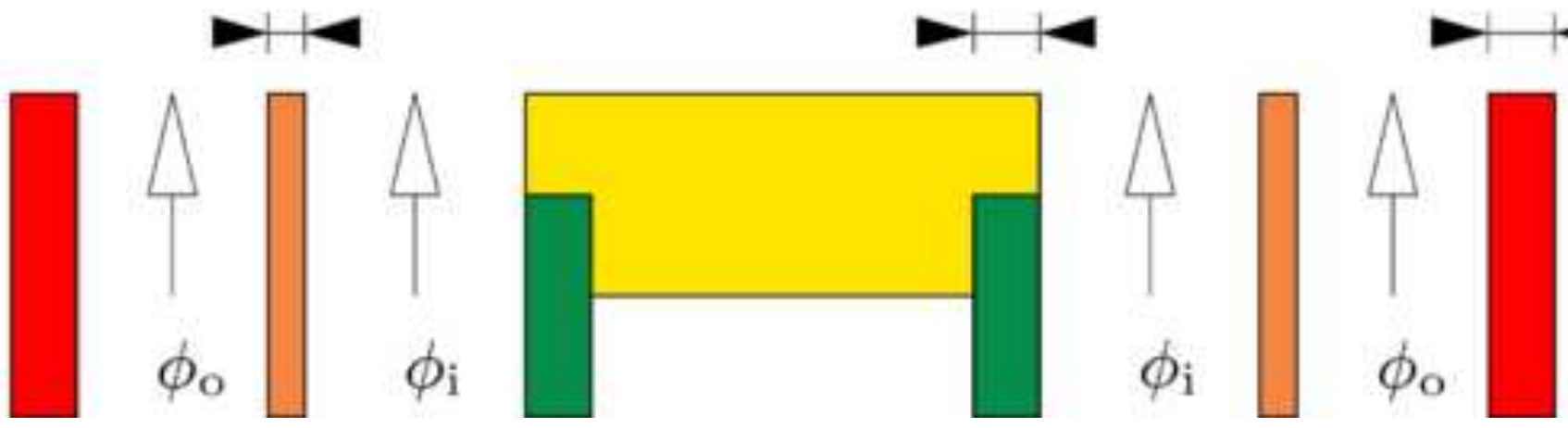
Click here to download high resolution image

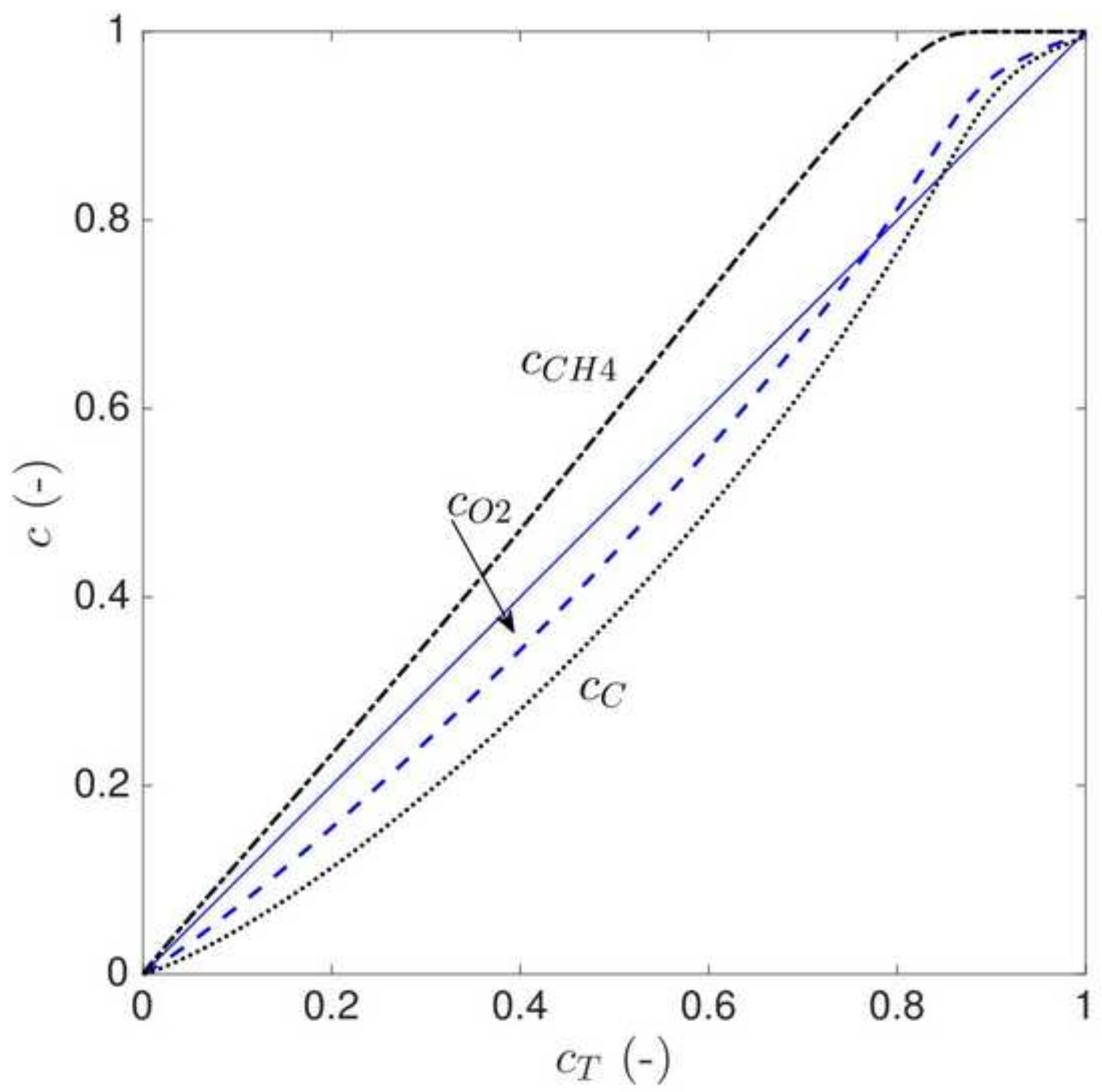


Click here to download high resolution image

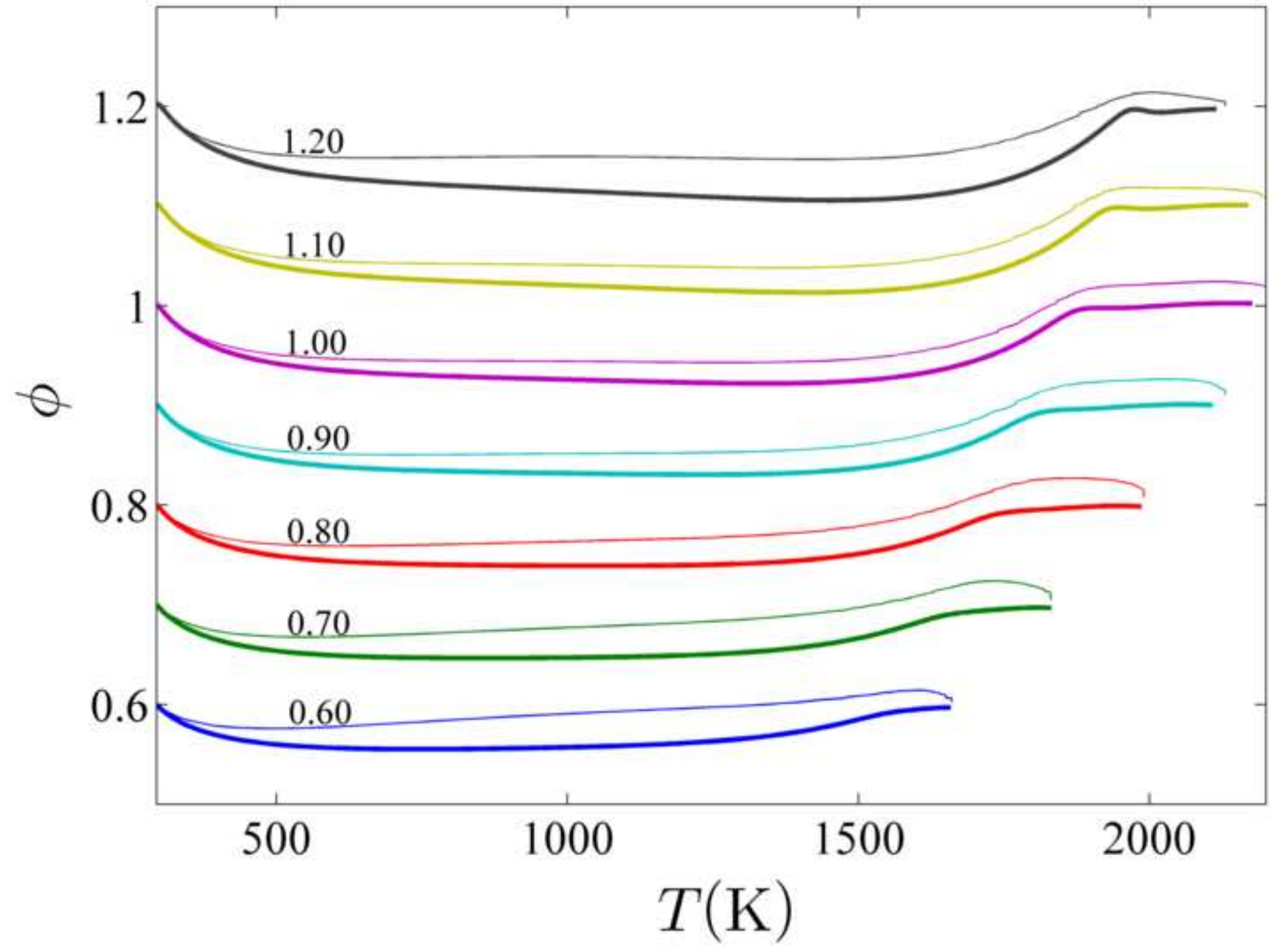


SwB1

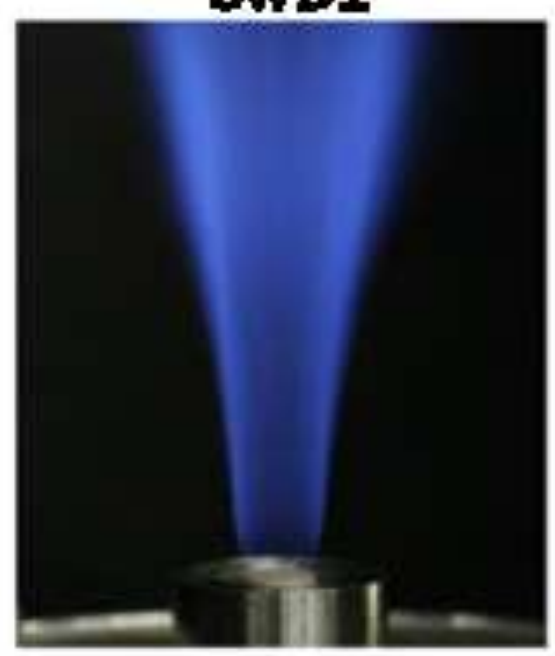

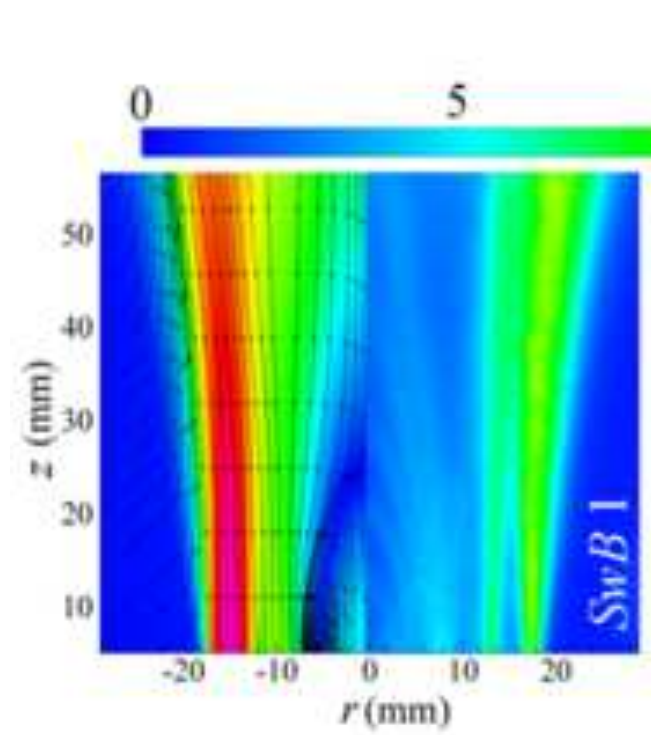

SwB1: $\phi$

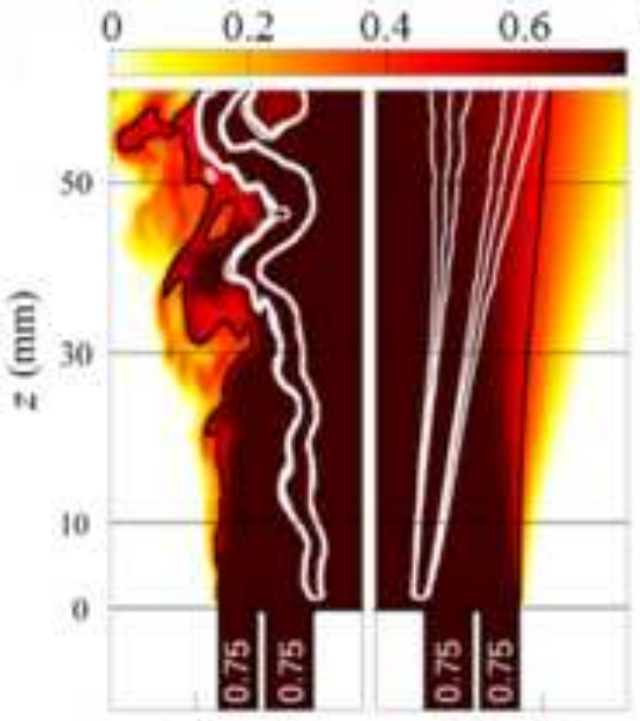

$-20 \quad+10$

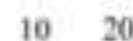
$r(\mathrm{~mm})$

SwB5

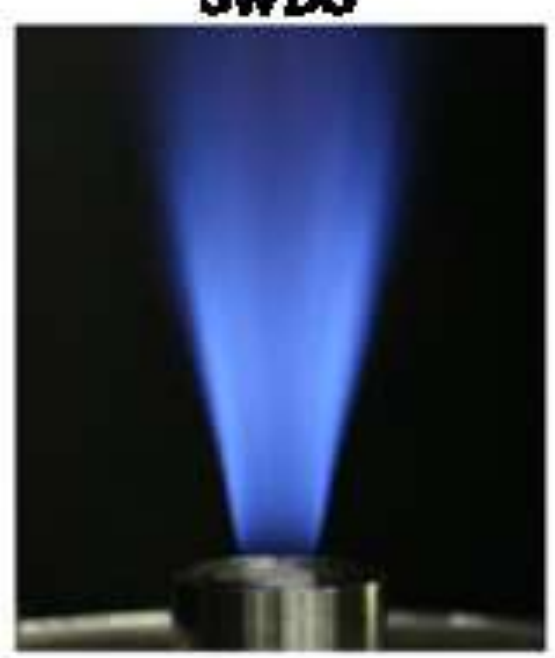

U. $3 U^{\prime}(\mathrm{m} / \mathrm{s})$
15 20
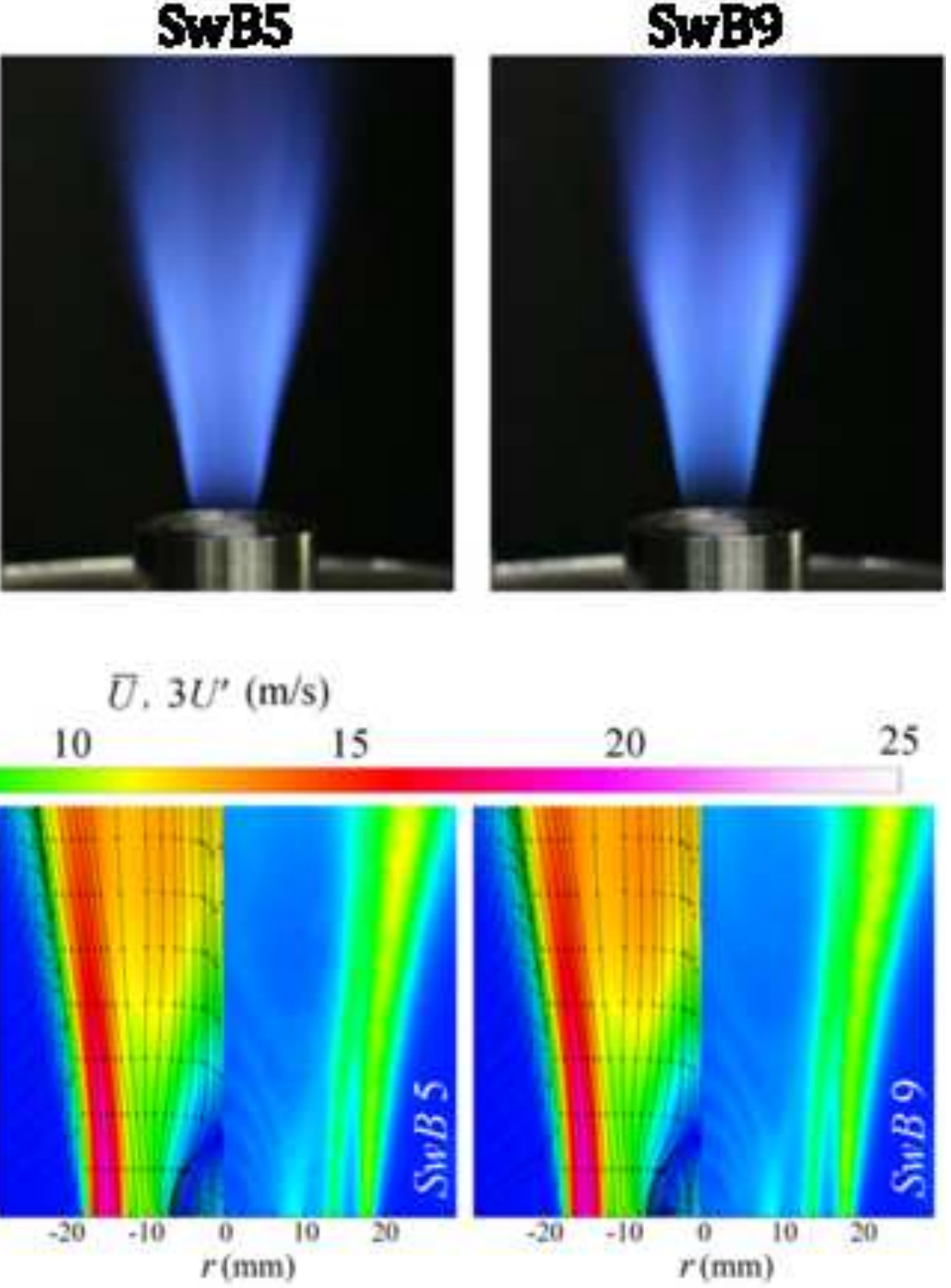

SwB5: $\phi$

SwB9: $\phi$
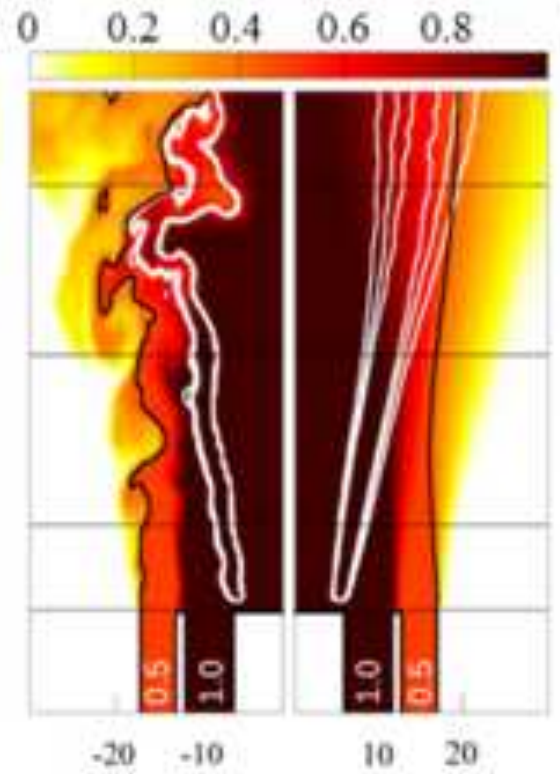

$10 \quad 20$ $r(\mathrm{~mm})$

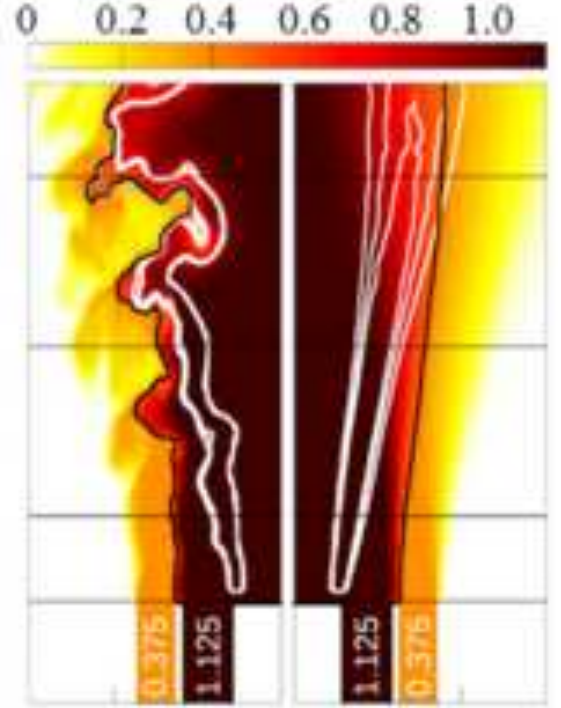

$-20 \quad-10$ $10 \quad 20$ $r(\mathrm{~mm})$ 


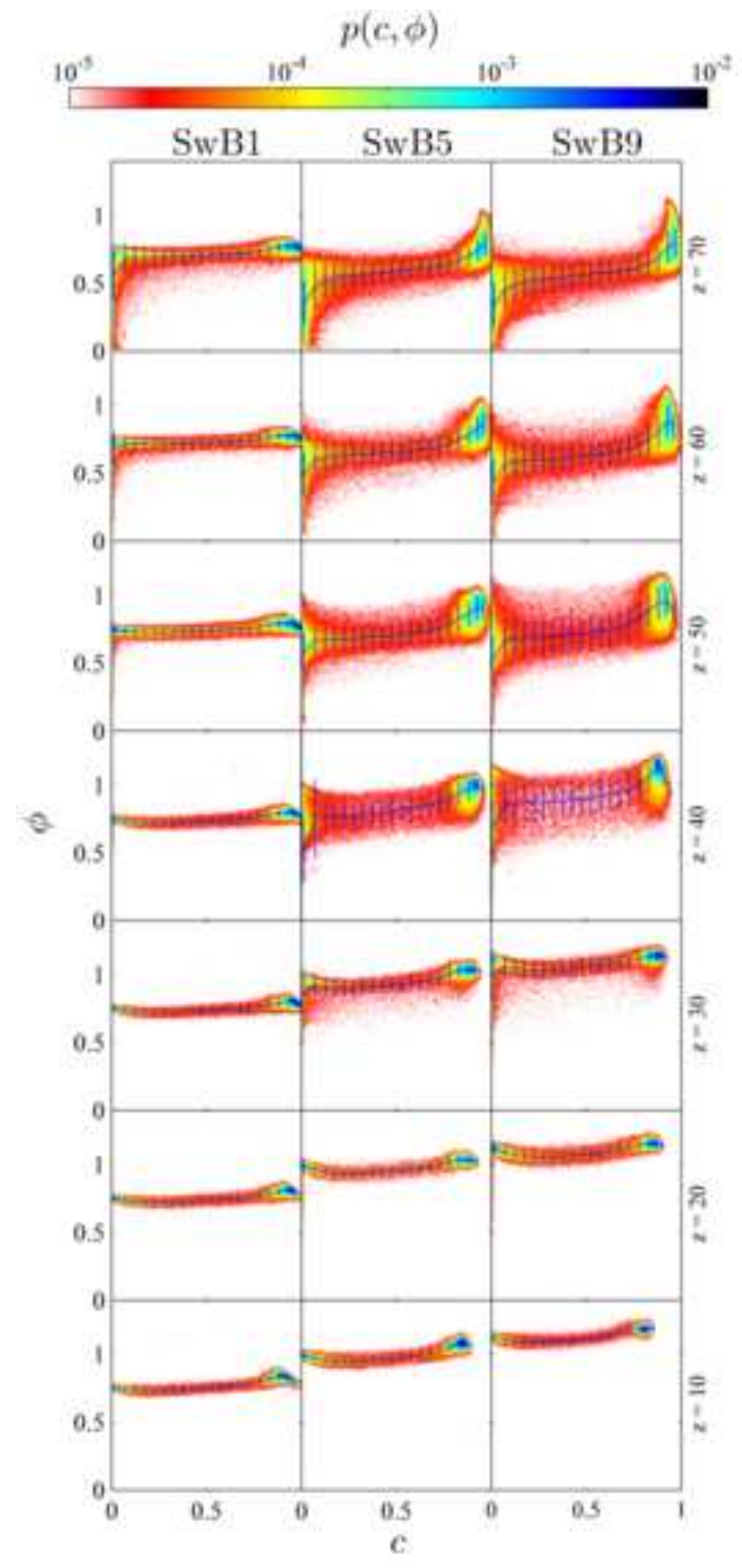

(a)

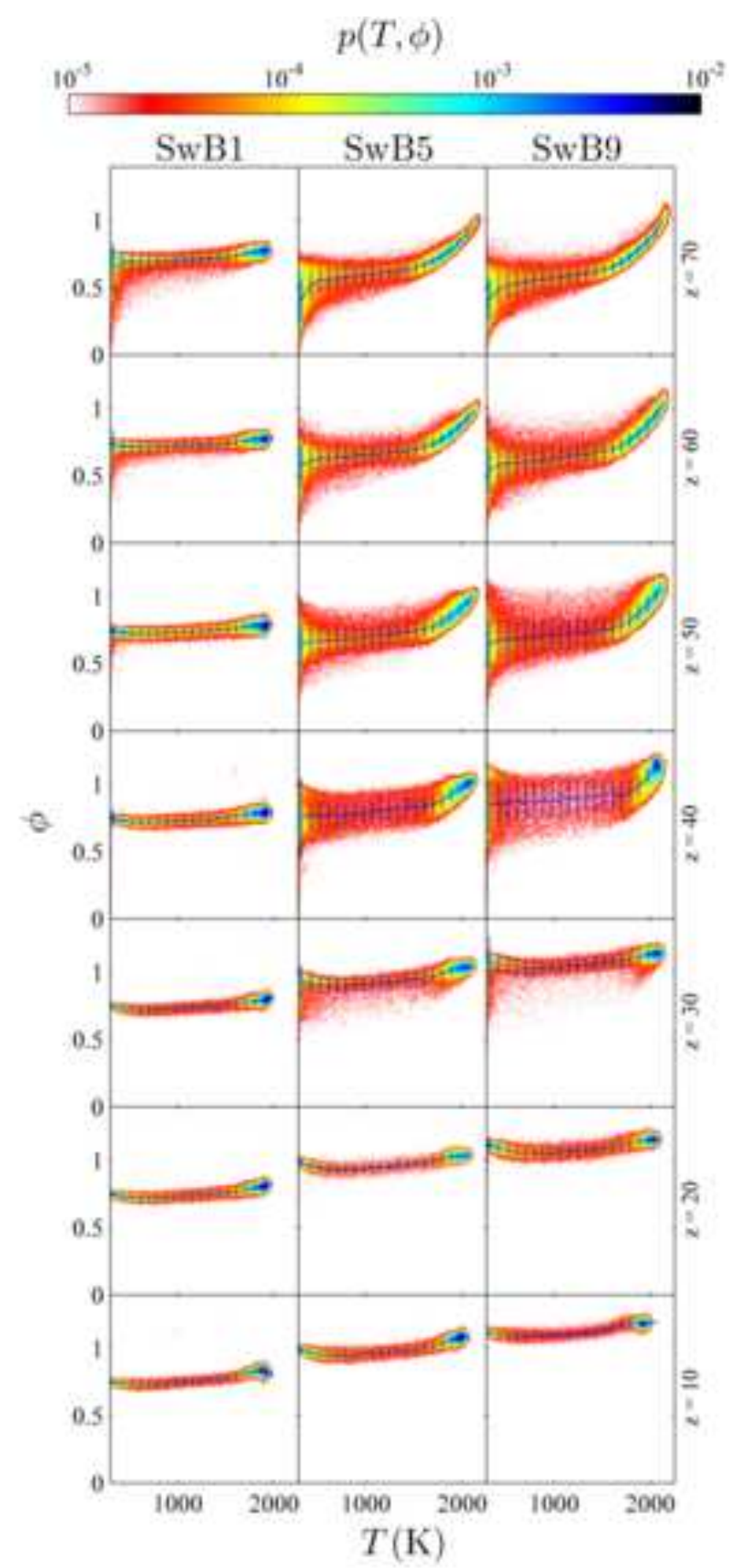

(b) 


\section{Figure-}

Click here to download high resolution image

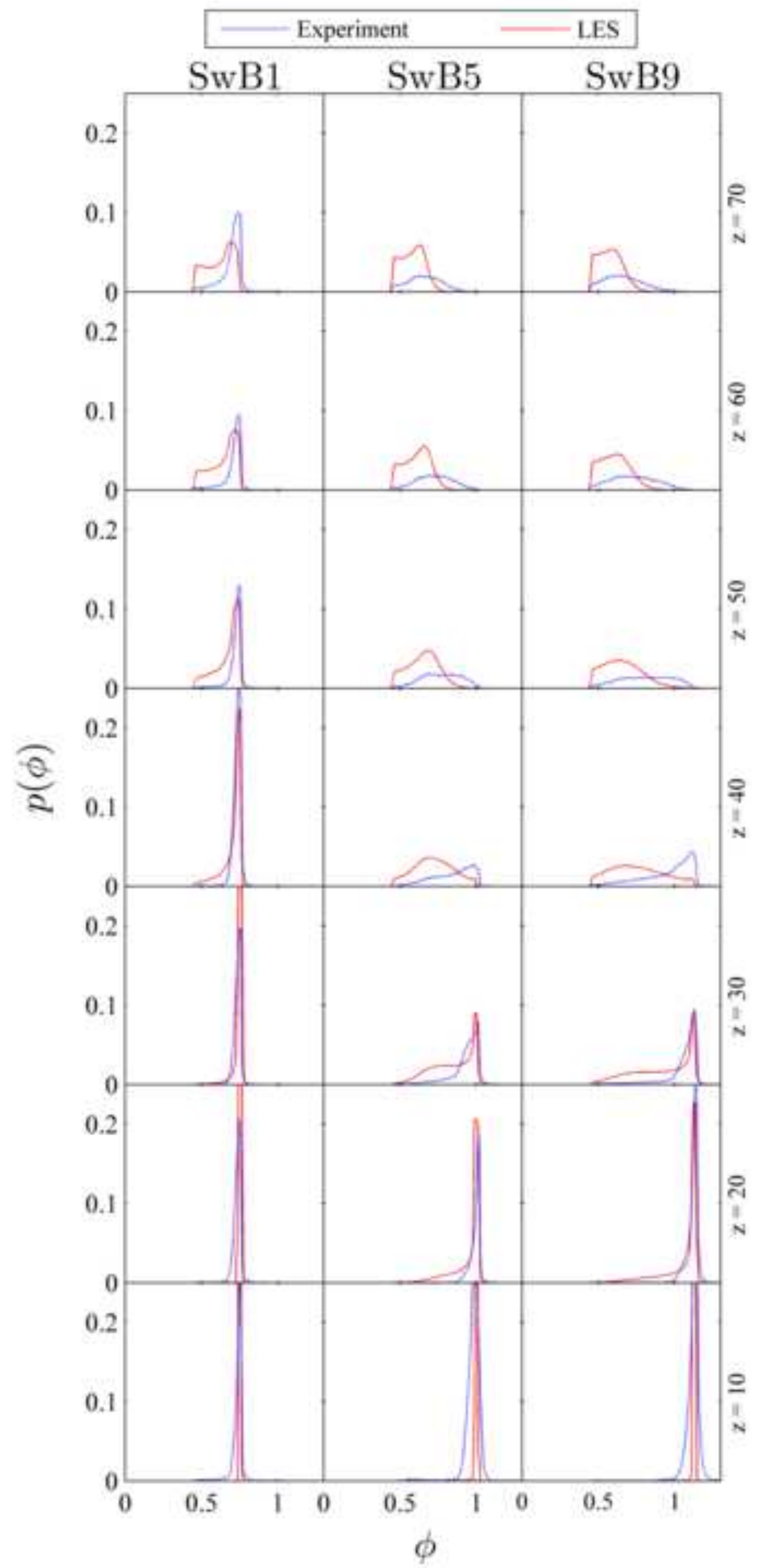



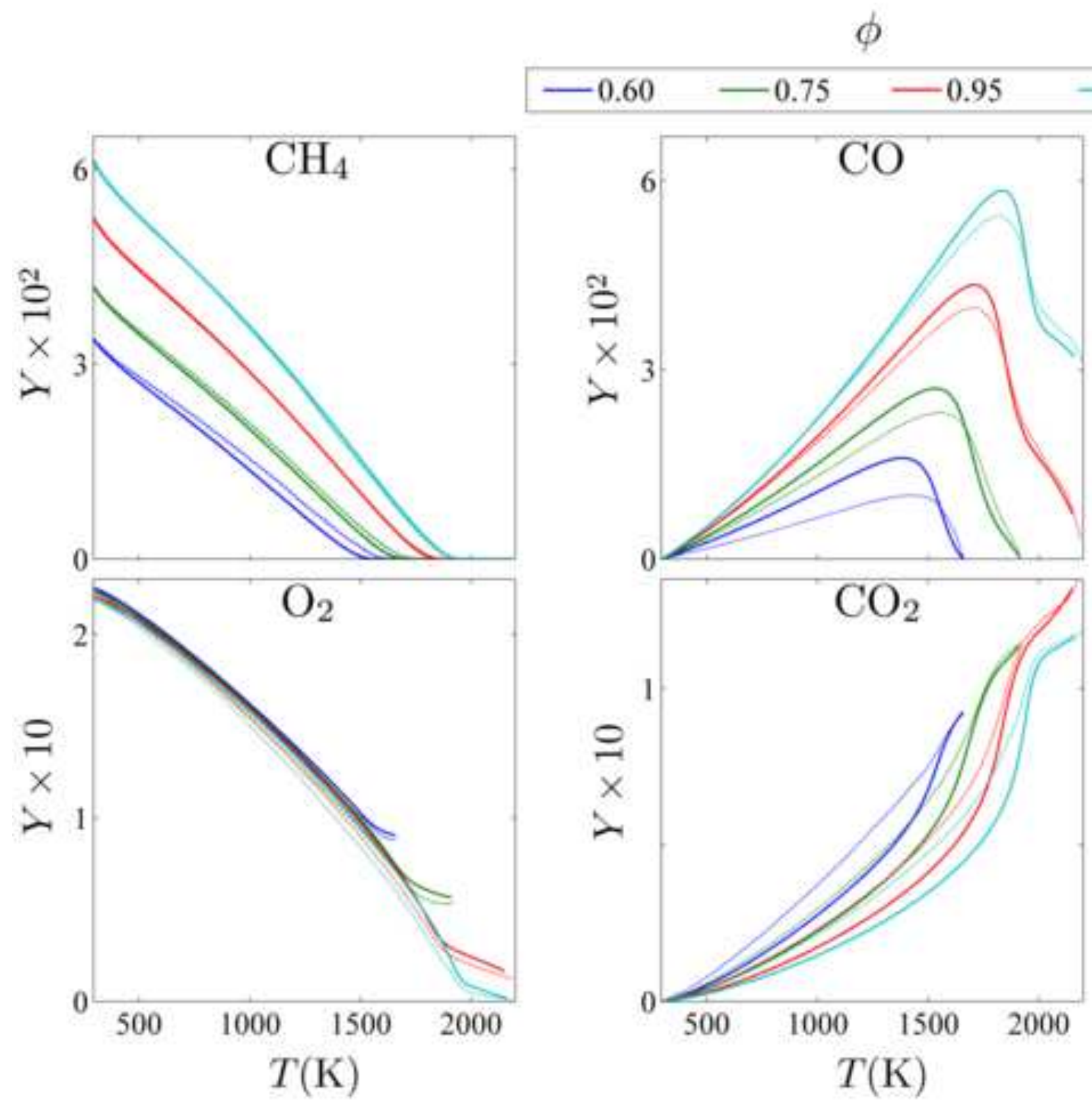
Figure-8

Click here to download high resolution image

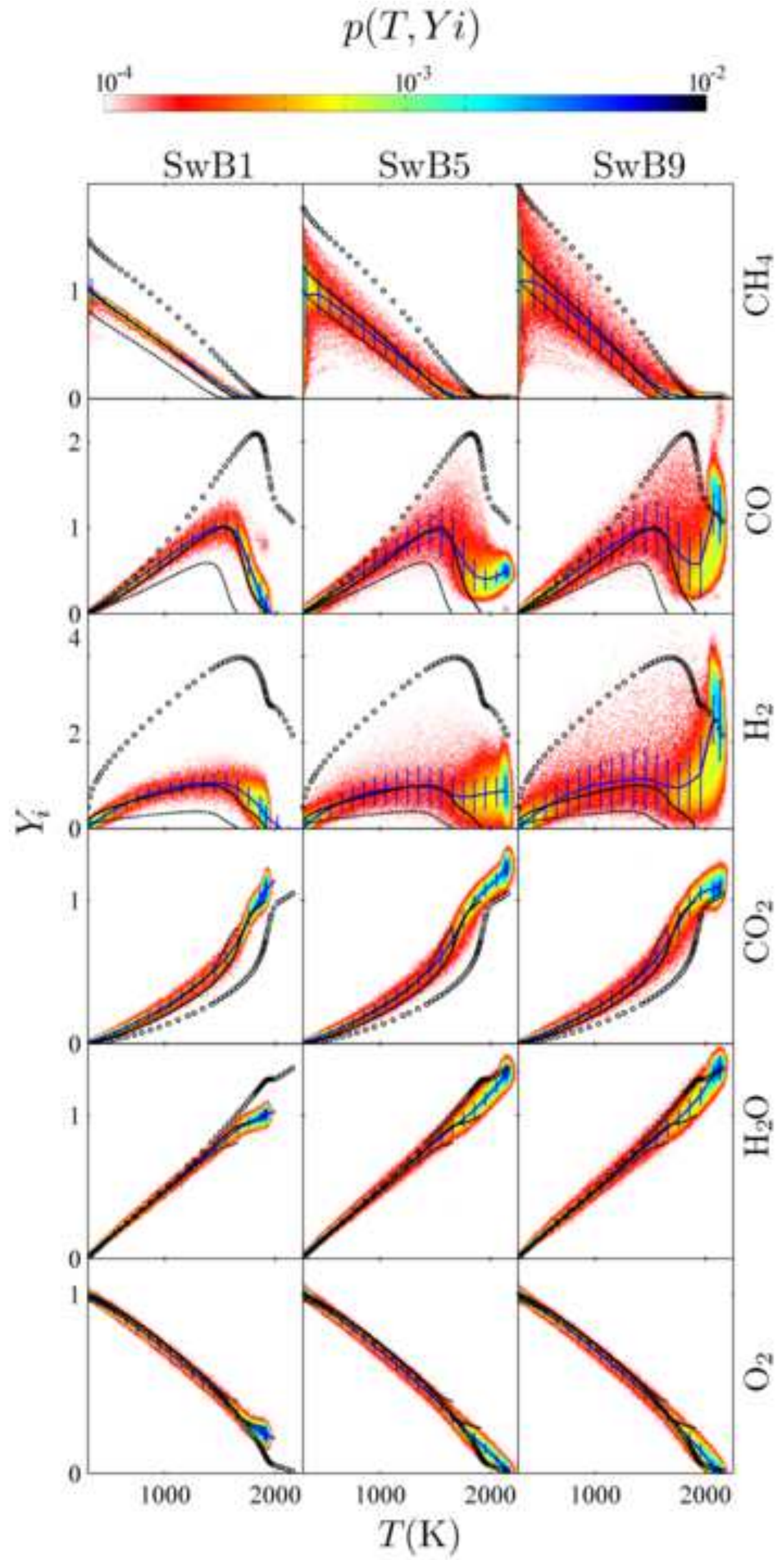


Figure-9
Click here to download high resolution image

Figure-9
Click here to download high resolution image

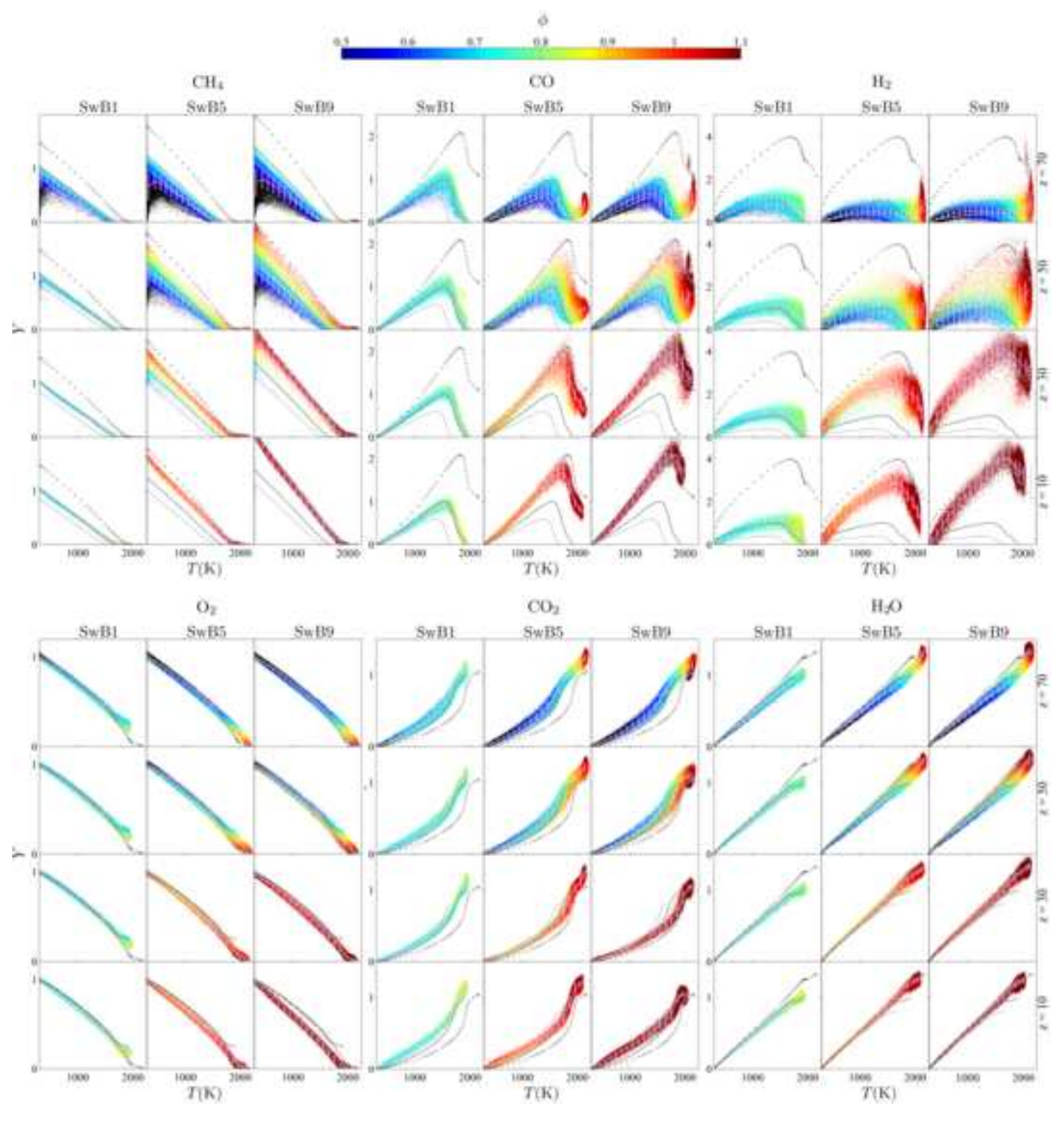

.

.


Click here to download high resolution image

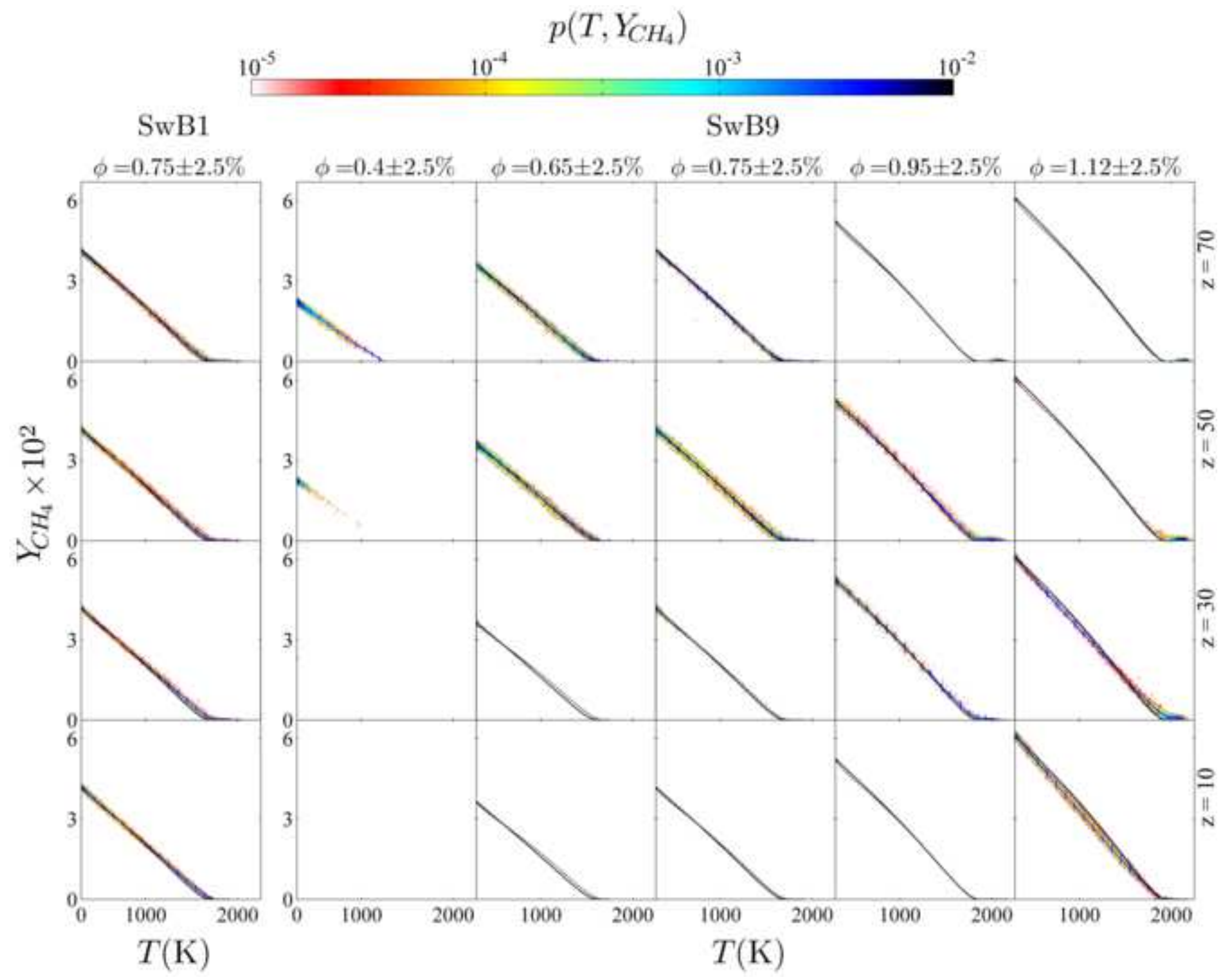


Click here to download high resolution image

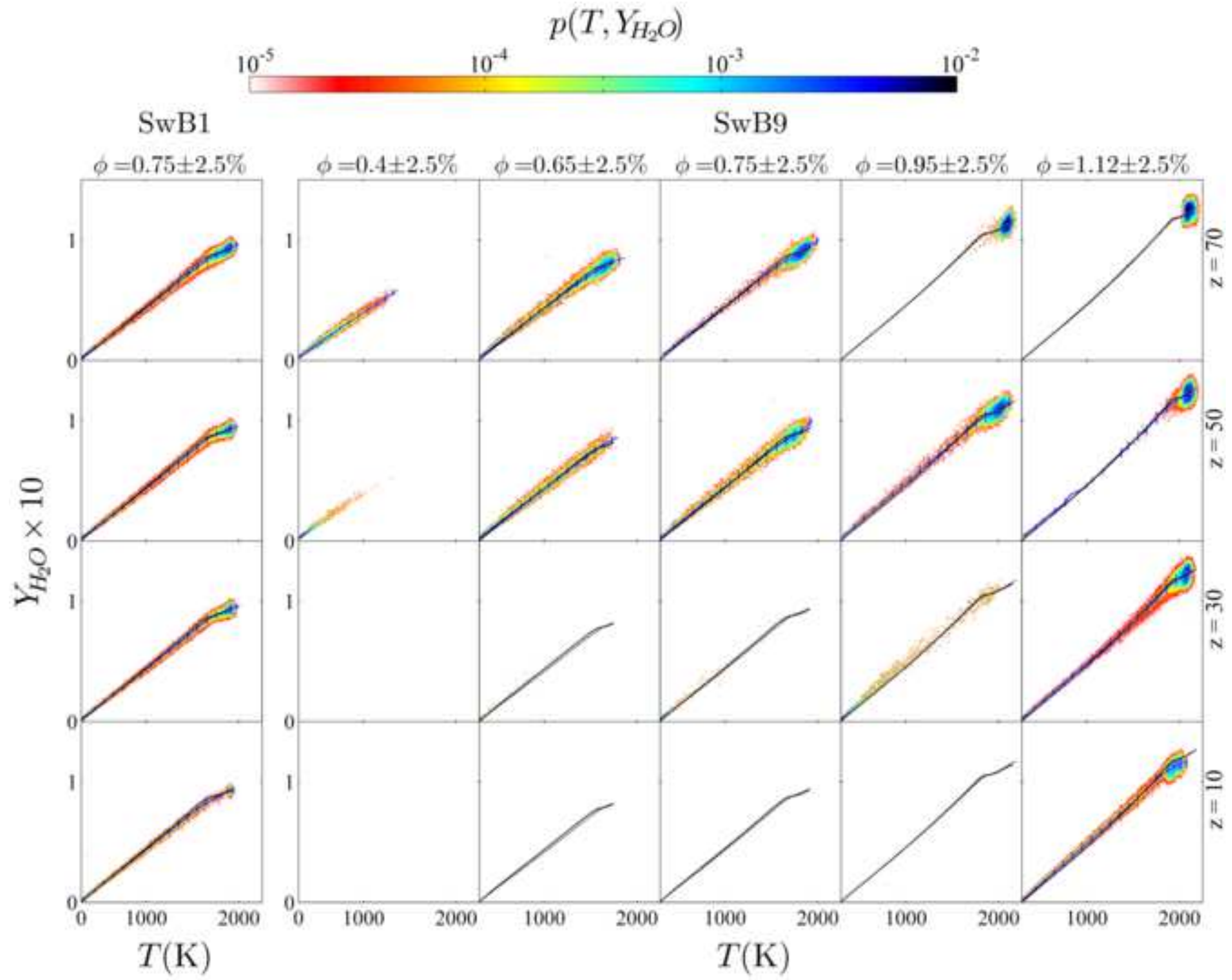


Click here to download high resolution image

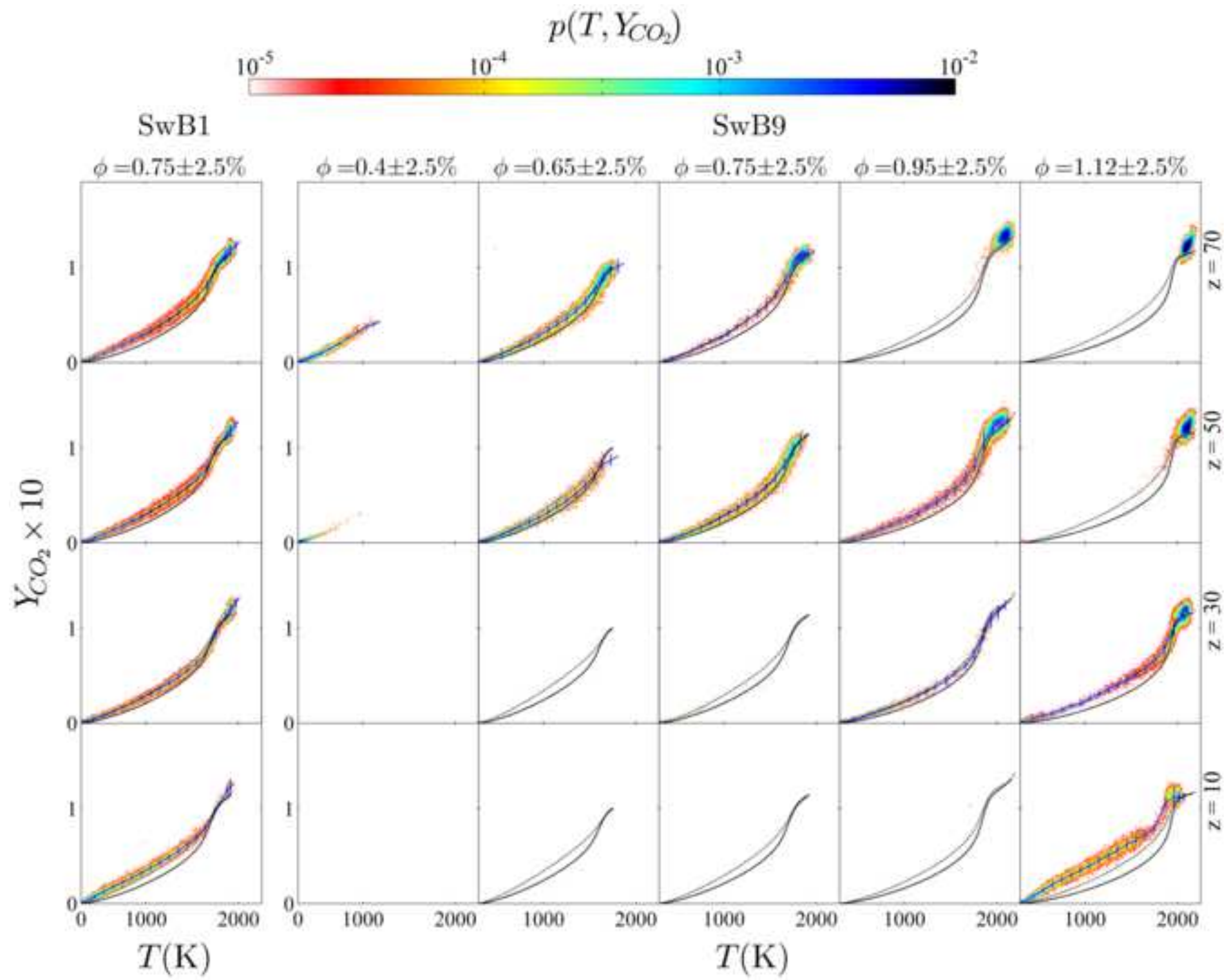




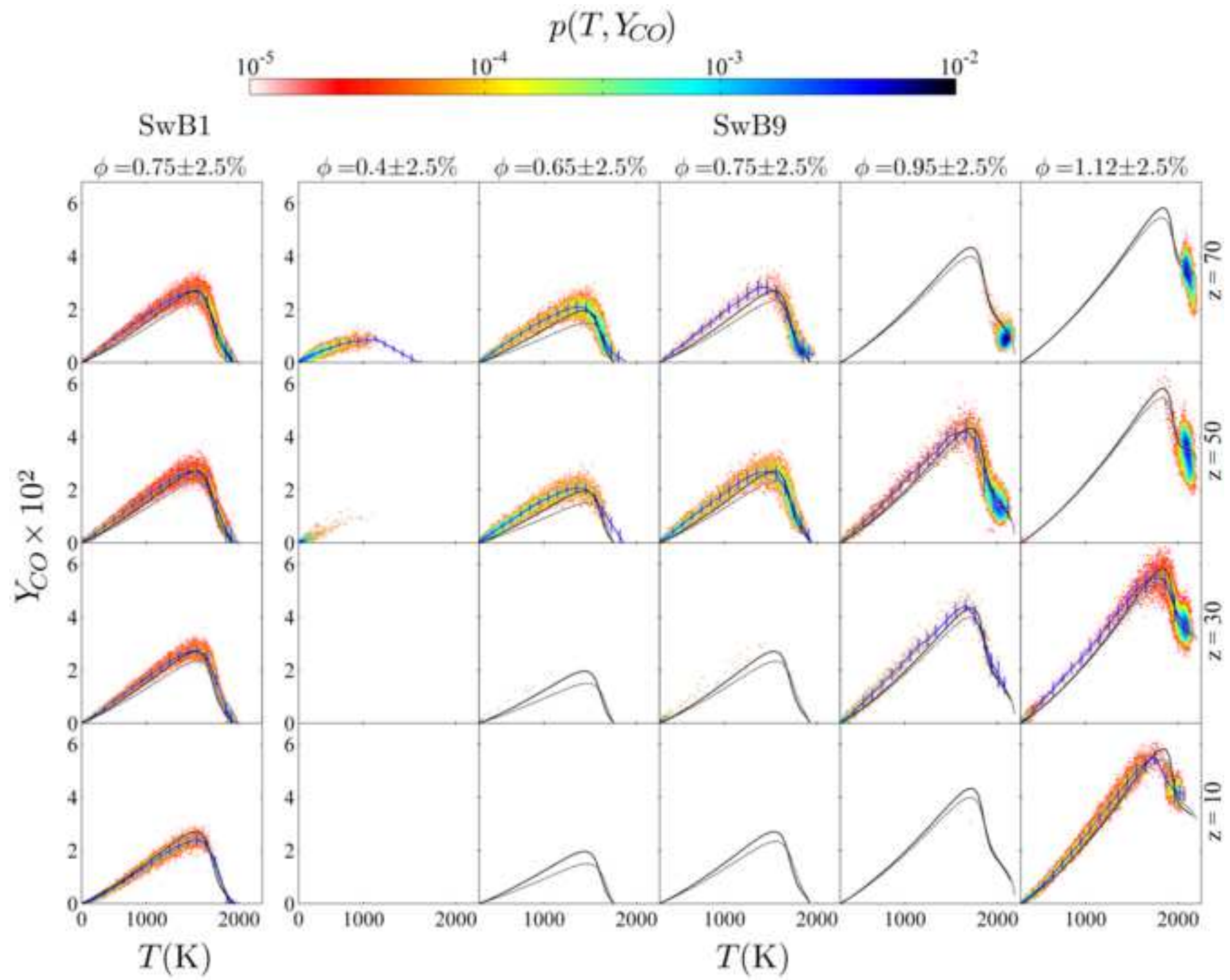


Click here to download high resolution image

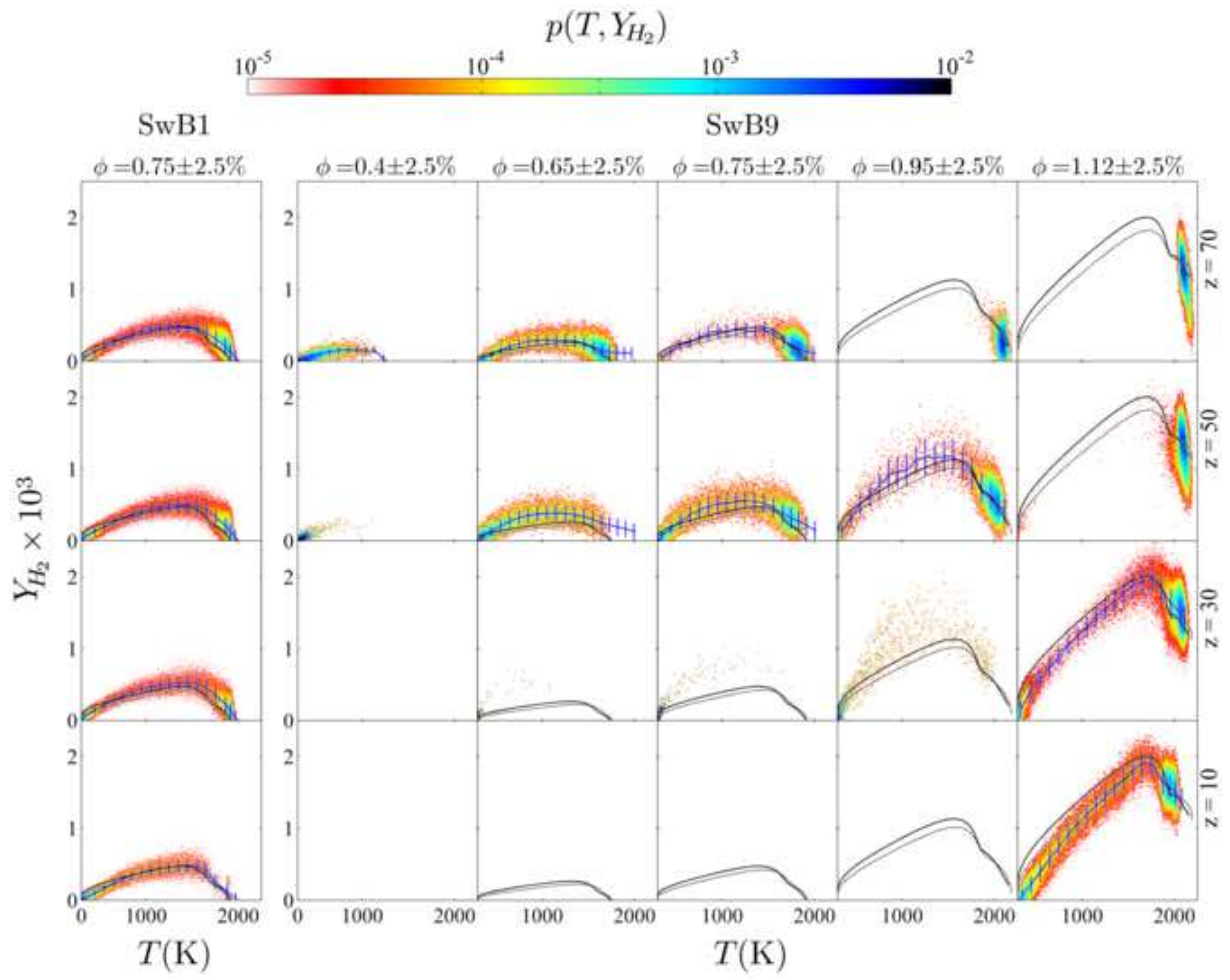




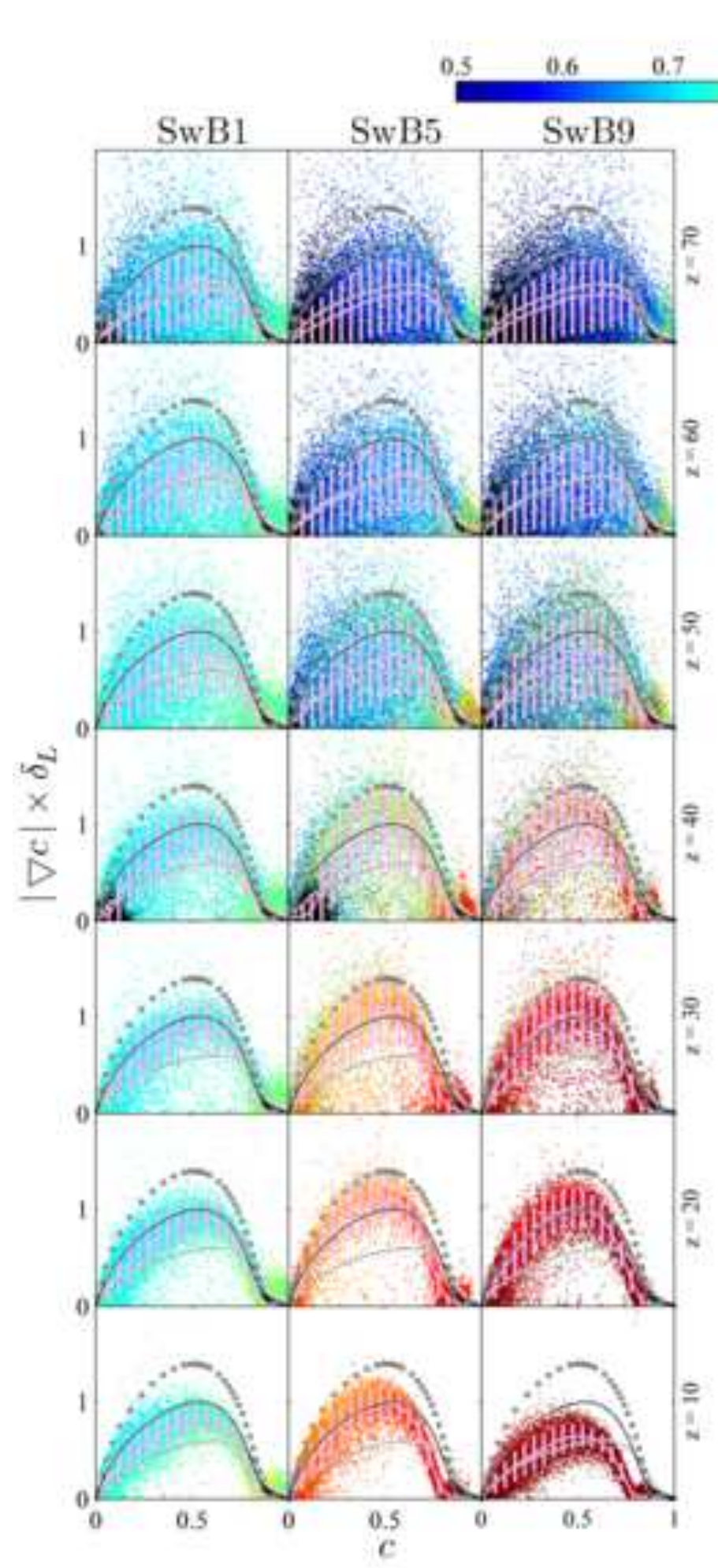

(a)

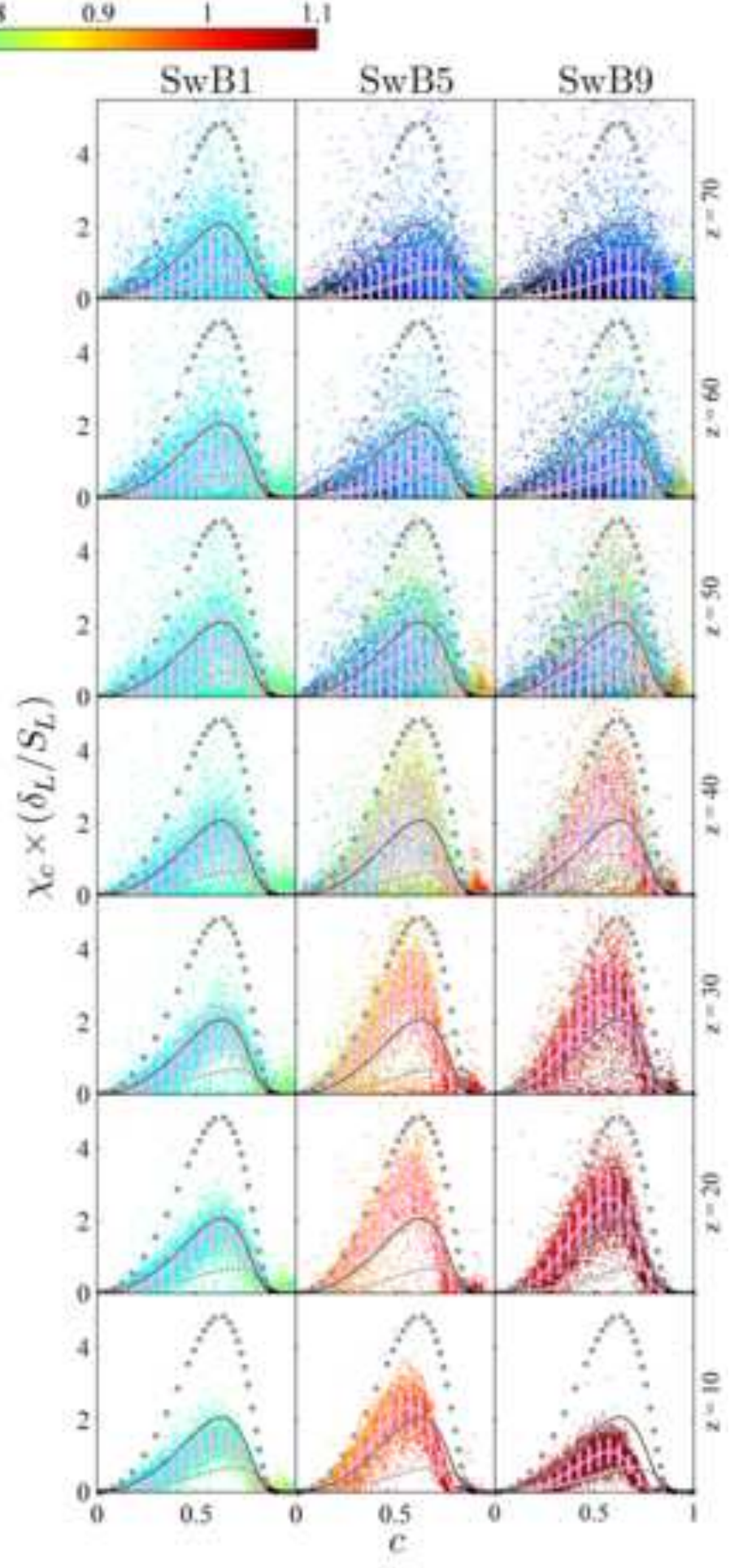

(b) 
Click here to download high resolution image

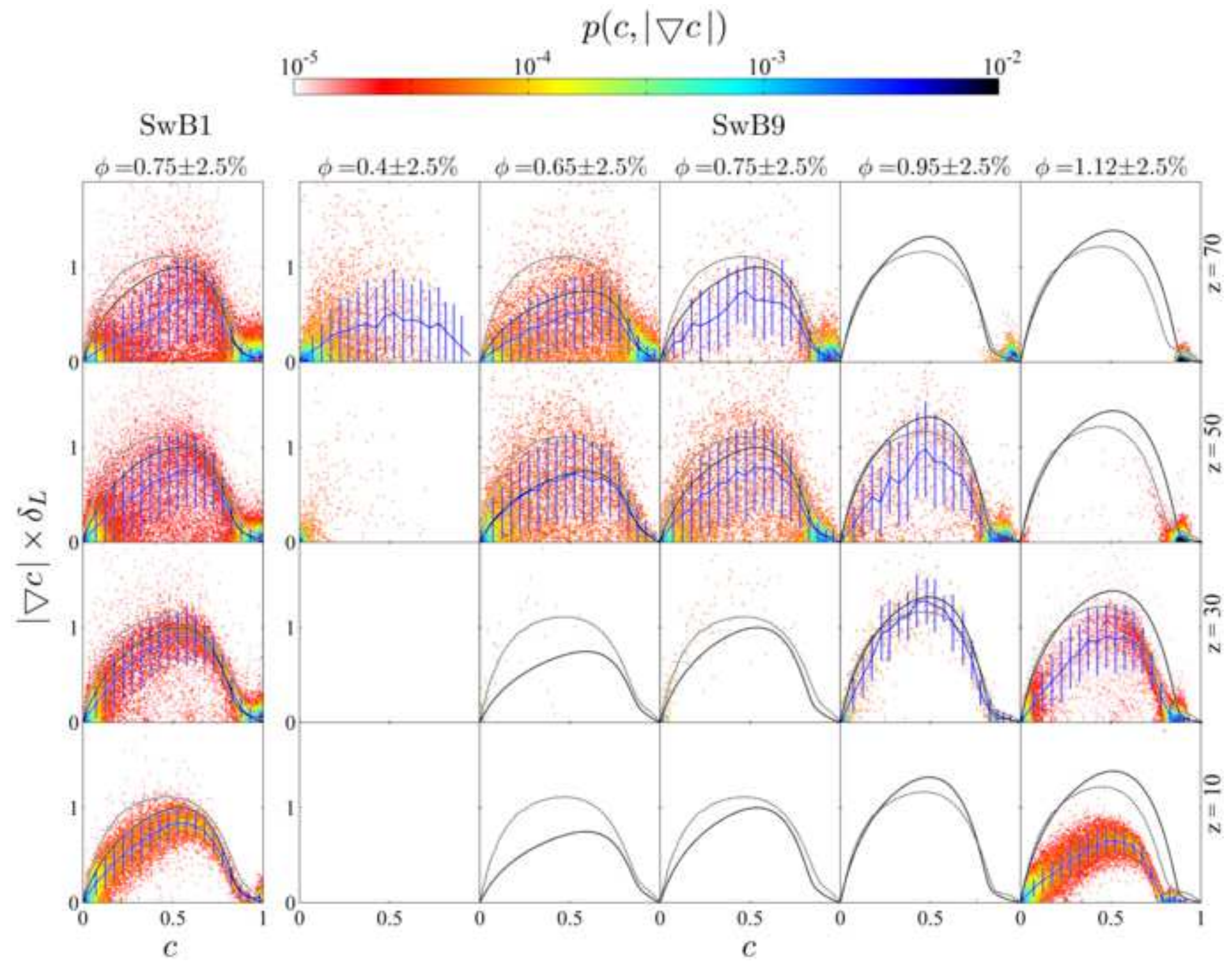




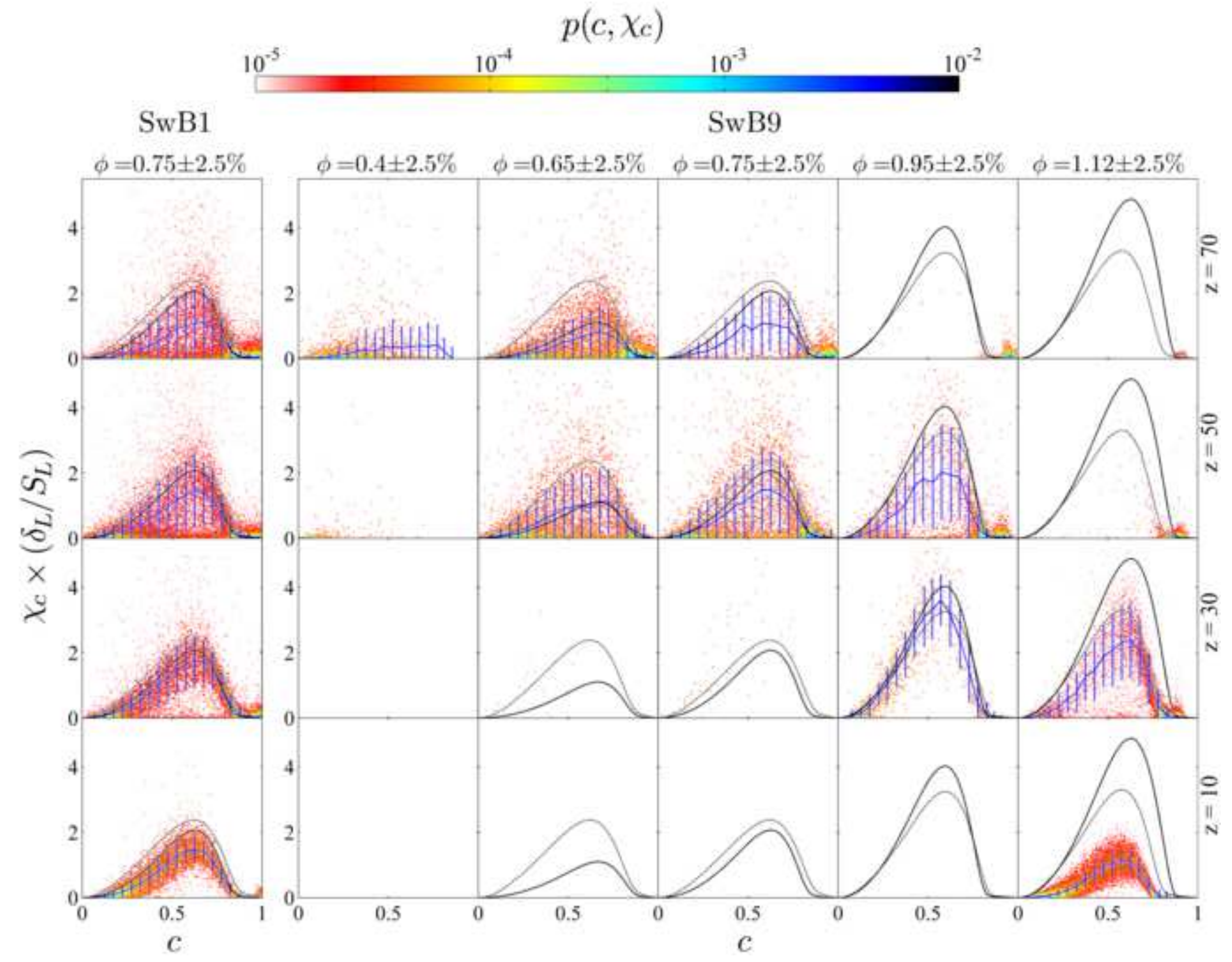

